\title{
Building assets for safe, productive lives: A report on a workshop on adolescent girls' livelihoods
}

Population Council

Follow this and additional works at: https://knowledgecommons.popcouncil.org/departments_sbsr-pgy

Part of the Demography, Population, and Ecology Commons, Family, Life Course, and Society Commons, Gender and Sexuality Commons, Gender Equity in Education Commons, and the International Public Health Commons How does access to this work benefit you? Let us know!

\section{Recommended Citation}

"Building assets for safe, productive lives: A report on a workshop on adolescent girls' livelihoods." New York: Population Council, 2005. 


\section{building assets \\ for safe, productive lives}

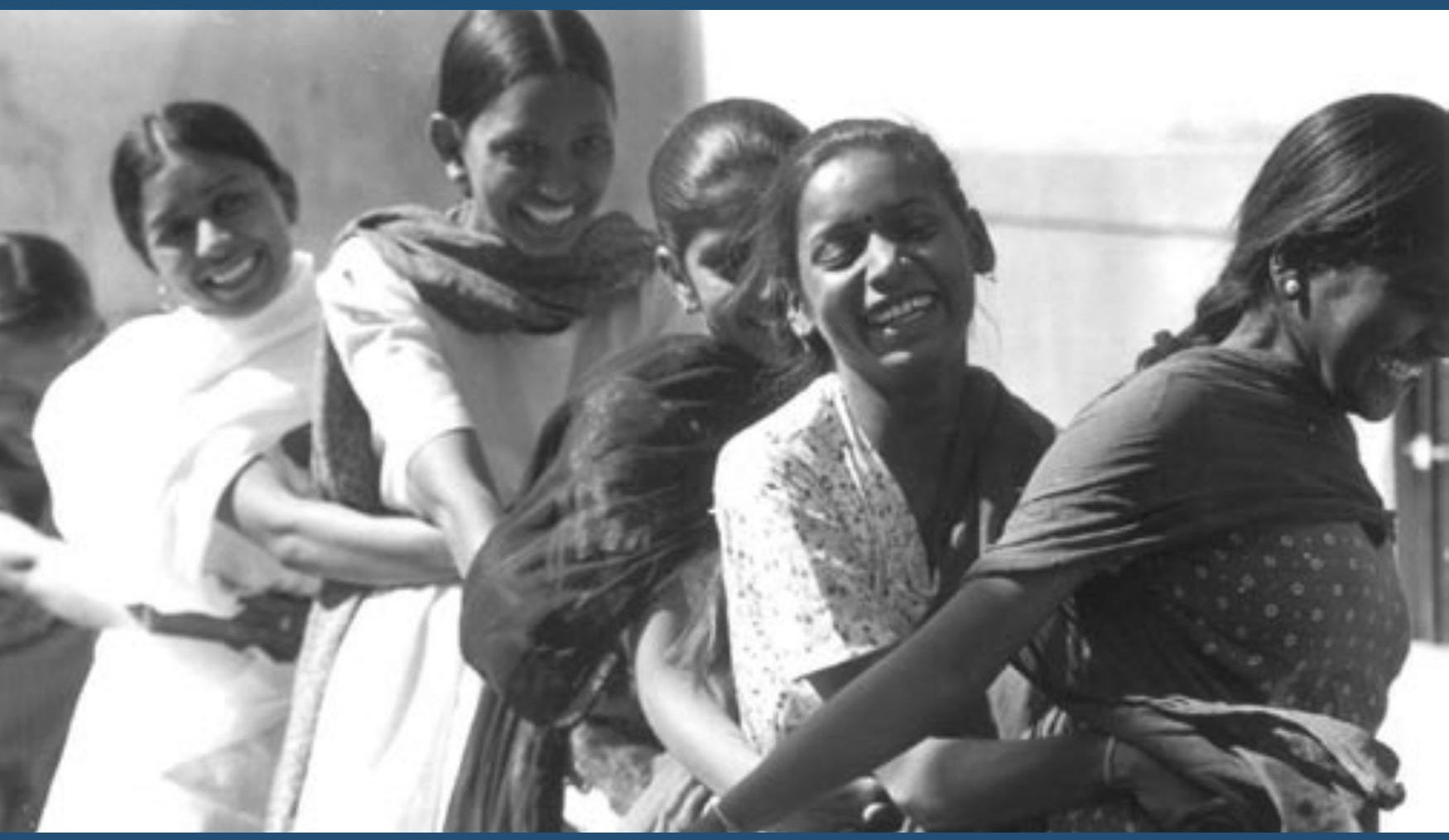

a report on a workshop on adolescent girls' livelihoods 


\section{building assets \\ for safe, productive lives}

a report on a workshop on adolescent girls' livelihoods

7-8 April 2004 


\section{(1) Pupdation Counat}

The Population Council is an international, nonprofit, nongovernmental organization that seeks to improve the well-being and reproductive health of current and future generations around the world and to help achieve a humane, equitable, and sustainable balance between people and resources. The Council conducts biomedical, social science, and public health research and helps build research capacities in developing countries. Established in 1952, the Council is governed by an international board of trustees. Its New York headquarters supports a global network of regional and country offices.

Population Council

One Dag Hammarskjold Plaza

New York, NY 10017 USA

212/339-0500; fax: 212/755-6052

e-mail: pubinfo@popcouncil.org

www.popcouncil.org

(C) 2005 by The Population Council, Inc.

Any part of this publication may be photocopied without permission from the authors or publisher, provided that publication credit is given and that copies are distributed free. Any commercial reproduction requires prior written permission from the Population Council. 


\section{Contents}

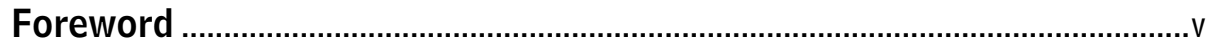

Acknowledgments ............................................................................................. vii

Reviewing the progress made over the past

five years: Opening remarks................................................................................. 1

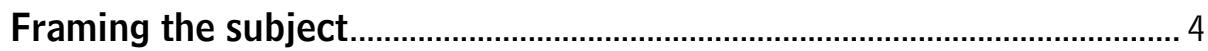

The social dimensions of livelihoods programming

for adolescent girls............................................................................................. 21

Clarifying problem statements, setting benchmarks, and developing tools.

Wrapping up and looking forward ................................................................. 42

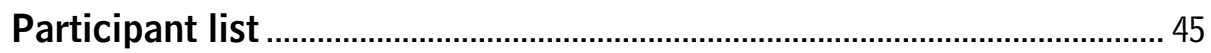




\section{Foreword}

The population of young people in developing countries has experienced unprecedented growth; as of 2005, the total number of 10-24-year-olds is estimated to have reached 1.5 billion. This figure represents nearly 30 percent of the population in these regions, and 86 percent of all young people in the world. The degree of success with which these young people navigate the social, psychological, economic, and biological transitions to adulthood will determine to a large degree not only the nature and quality of their future lives, but the economic stability and development of their nations.

The transition to economic productivity is among the pivotal transitions young people make as they grow older. Particularly for the roughly 325 million young people in developing countries growing up on less than $\$ 1$ a day, the failure to acquire marketable skills or capabilities for lifelong learning may consign them to persistent, deepening poverty. Girls face a special set of challenges, as adolescence may bring confinement, on the one hand, and an increased demand by their families for support on the other. The economic support role that girls play can begin early (indeed, sometimes earlier than that of their brothers) and extend long into adulthood; a rising proportion of families all over the world are either solely or substantially supported by women. Fulfilling this role can be extremely difficult in settings where females have less access than males to critical resources such as secondary school education, credit, land, training, and technology. Girls' worlds are often circumscribed during adolescence as they are withdrawn from school and experience a stark decline in their friendship networks and general freedom. Without this social capital and the confidence that goes with it, girls do not establish themselves as decisionmakers even within their families, nor as citizens in their communities, and are unlikely to succeed as economic actors.

Not only do boys and girls have very different trajectories, but there are growing differences among young people within and across countries; some young people progress while others are left behind. The extensive National Academy of Sciences Report Growing Up Global: The Changing Transitions to Adulthood in Developing Countries identifies sub-Saharan Africa as a region of special concern, where rising rates of poverty have limited declines in children's labor-force participation and increases in school enrollment, and where war, civil conflict, and the HIV epidemic (which is tragically increasingly selective not only of the young, but of young girls) have created a treacherous environment. Slow economic growth combined with an expanding population have contributed to high rates of unemployment among the young in this region as well. 
The livelihoods approach considers the capabilities, assets, and activities required for making a living, and is a constructive framework through which to weave together all the different strands of self that a young person requires to be economically successful-an enquiring mind, decisionmaking authority, and a set of social and economic skills. This report summarizes the proceedings of a workshop on adolescent girls' livelihoods that brought together stakeholders from all over the globe to interpret the word "livelihoods" in light of the needs of adolescents, and to review recent findings from field-based interventions and the research methods necessary to bring to light the distinctive adolescent experience. The field has moved far beyond addressing the question of "why livelihoods for adolescents?" to refining "how best to provide livelihoods" answers.

In the course of the workshop held at the Population Council in New York, 7-8 April 2004, we considered complementarities and tradeoffs between adolescent work and school, as well as the role of marriage in girls' livelihoods strategies.
Findings were presented on programs directed to this age group that seek both to build traditional economic skills and to offer social support. Programs reviewed in India, Kenya, and Egypt, for example, sought to increase the agency and decisionmaking power of young women by building social networks and securing access to safe spaces. Data from South Africa were used to draw out the linkages between economic vulnerability and health behaviors in the context of the HIV epidemic. For girls, economic vulnerability has been found to increase the likelihood of exchanging sex for money or goods, experiencing coerced sex, and not using a condom at last sex. Participants grappled throughout the proceedings with the vast internal diversity of the adolescent experience requiring different program approaches by age, sex, urban-rural setting, economic vigor of the economy, and stage of development. Thus, we cannot simply adapt what we know about adults to adolescents. We hope the reader will appreciate adolescents' internal diversity and see the need for continual experimentation and learning.

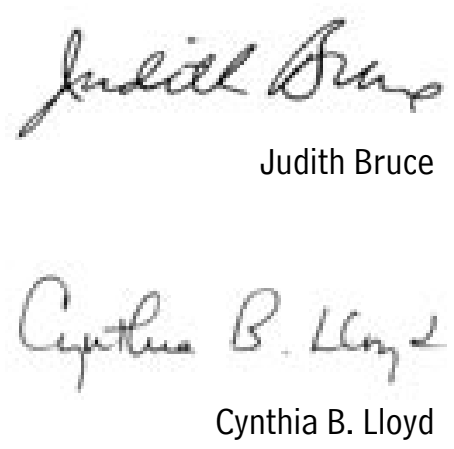




\section{Acknowledgments}

We wish to thank the United Kingdom Department for International Development (DFID), the Bill and Melinda Gates Foundation, the Dickler Foundation, the Turner Foundation, the Ford Foundation, the Rockefeller Foundation, the William H. Kaufman Foundation, the Summit Foundation, the United States Agency for International Development, United Nations Fund for Children, United Nations Fund for Population Activities, the United Nations Foundation, the John D. and Catherine T. MacArthur Foundation, the William and Flora Hewlett Foundation, the Andrew W. Mellon Foundation, the Libra Foundation, and Ms. Effie E. Westerveldt for program and/or project support of the Population Council's work in adolescent social development and livelihoods in recent years.

Erica Chong served as meeting rapporteur, conceptualized the report, and wrote each summary. However, the report represents the collaborative work of many: Sara Rowbottom and Michelle Skaer acted as notetakers; Jennefer Sebstad offered invaluable comments and text contributions; and Judith Bruce, Carey Meyers, Kelly Hallman, Cynthia Lloyd, and Sajeda Amin provided insightful comments and guidance. We thank Karen Tweedy-Holmes, Mike Vosika, and Christina Tse for their skillful editing and production support. 


\section{Reviewing the progress made over the past five years: Opening remarks}

Judith Bruce of the Population Council opened the meeting by describing the intellectual lineage of the work on adolescent girls' livelihoods. The first meeting on this subject, convened by the Population Council and the International Center for Research on Women in October 1999 in Cairo, was part of the effort to reposition the adolescent agenda from one focused on reproductive health behaviors and outcomes and adolescent risk-taking to one that encompassed the broader social and economic dimensions of vulnerable adolescent girls' lives during their transition from childhood to adulthood in poorer countries.

One of the major concerns that emerged at the Cairo adolescent livelihoods meeting was the dearth of information regarding adolescents' work, livelihoods, and time use upon which policies and interventions were based. Some progress has been made since the first meeting both in the improvement of datacollection methods and in the aggregation and analysis of information about the informal sector, child labor, and unpaid work. Notable efforts include those undertaken by Women in Informal Employment Globalizing and Organizing (WIEGO) and the Statistical Information and Monitoring Programme on Child Labour (SIMPOC), and the (then forthcoming, now available) National Academy of Sciences review entitled Growing up Global: The Changing

\section{Transitions to Adulthood in Developing Countries.}

Ms. Bruce emphasized the importance of exploring the internal diversity of adolescents in terms of their preparation for work and work experience. She cautioned against homogenizing their needs (particularly across the broad age spectrums that are increasingly defined as youth, which in some countries include those as old as 30), either as a group or in contrast with adults. Commenting on global data for four categories of adolescents classified by work and schooling status (see Table 1), she asked, "Which of these adolescents do we care about?" The answer was that we care about all of them, but for different reasons.

For adolescents who only work, we must learn what pushes them into work, particularly at an early age; what are the benefits and costs; and what are the tradeoffs with education. Of special concern are those aged 10-14, who ought to be in school. For those older adolescents who are at work and at school, we need to know when their situation is advantageous and when it is not. Are there ways in which work and school can be combined effectively? For those who are in school but do not work, is school preparing girls and boys equally —or at all—for the world of work? Lastly, adolescents who are neither at school nor at work may deserve 
Table 1 Percentage distribution of children by activity status, global estimates, 2000

\begin{tabular}{lcc}
\hline Activity status & 10-14-year-olds & 15-17-year-olds \\
Number of children (thousands) & 599,200 & 332,100 \\
Percentage who work & 23.0 & 42.4 \\
At work only & 13.1 & 31.1 \\
At work and at school & 9.9 & 11.3 \\
Percentage at school, but not at work & 66.9 & 43.4 \\
Percentage neither at school nor at work & 10.1 & 14.2 \\
\hline
\end{tabular}

Source: ILO (2002).

special attention, because they may be the most vulnerable of all, disconnected from school and sometimes from protective family structures, with no safe or productive path between childhood and adulthood.

Ms. Bruce reviewed the evolving livelihoods approach and the attention it directs to the social underpinnings and parameters of poverty alleviation. The livelihoods approach looks far beyond income and conventionally defined assets to gauge individuals' overall well-being. It considers factors such as social isolation, poor health and health-seeking behaviors, residential stability and home life, and agency. This analytic framework inventories individuals' capabilities (what a person can do or be, as defined by Amartya Sen); their assets in four categories (physical, financial, human, and social); and their activities (production, consumption, and investment activities) (see Box 1). These dimensions are viewed together, defining positive or negative prospects for adequate and flexible livelihoods over the person's life cycle.

The livelihoods approach is closely allied in spirit to the Decent Work Initiative, which connects work with social justice and inclusion. Juan Somavia, the DirectorGeneral of the International Labour Office

\section{Box 1 Assets}

Assets serve to reduce vulnerability and expand opportunities, and can include:

Human assets - skills and knowledge, ability to work, good health, self-esteem, bargaining power, autonomy, control over decisions

Financial assets - cash, savings, loans and gifts, regular remittances or entitlements Physical assets - land, housing, jewelry, shoes, clothing, productive assets, tools and equipment for business activities

Social assets - social networks, group membership, relations of trust, access to wider institutions of society, freedom from violence 
(ILO), has characterized the goals of the Decent Work Initiative in these terms:

\section{It is about gender equality, equal recognition, and enabling women to make choices and take control of their lives. In the most extreme situations, it is about moving from subsistence to existence. For many, it is the primary route out of poverty.... And everywhere, and for everybody, decent work is about securing human dignity (Blenk 2002).}

Ms. Bruce expressed her hope that the wide breadth and passionate tone conveyed in this quotation would be maintained in the conversations to follow.

The task of the meeting was set at exploring how best to build adolescent girls' and boys' capabilities and assets in ways that both reduce their vulnerability and expand their opportunities. Not only have many current income-generating and economic programs been built around adult paradigms, but often, inadvertently, their participants have been drawn disproportionately from those who are better-off, older, attending school, and male. Reducing adolescents' vulnerability through live- lihoods programs that build social support makes increasing sense, particularly in light of the AIDS pandemic, civil conflict, family mobility, and the disintegration of poor families.

Given the ready demand for productive opportunities on the part of adolescent girls and their parents (in even the most restrictive traditional circumstances), opportunities must be tailored accordingly. The internal diversity of adolescents and their differing and still-evolving capacities raise serious questions about the applicability of adult models. Ms. Bruce called for programs that are designed to pick up, include, and nurture those currently in fragile circumstances who are often excluded from conventionally configured programs for young people and adolescents. These include unschooled or out-of-school younger adolescents, adolescents living with neither parent (including AIDS orphans), girls at risk of or in child marriages, adolescents under pressure to exchange sex for gifts or money, and adolescent girls and boys in conflict situations. Step one for these young people may be to build up their social capacity and sense of personal agency, before productive work or assetbuilding opportunities can be seized. 


\section{Framing the subject}

This section examines how popular livelihoods strategies (such as vocational training, financial literacy, and microfinance) fit into the theoretical map of economic development and correspond with adolescents' evolving capacities, rapid transitions, and vulnerabilities. In addition, the relationship between livelihoods and two other major elements in adolescents' lives, school and marriage, are explored in depth. As recently as five years ago the political environment often posited the work and school relationship as an eitheror discussion, reflecting the attitude that the creation of work opportunities would pull adolescents out of school. The current discourse puts work and school in a much less antagonistic relationship. UNICEF has acknowledged that work can be protective in some settings, and UNFPA is an interested and involved partner in several adolescent livelihoods programs. The role of marriage in adolescent girls' livelihoods strategies are examined in four different country settings, focusing especially on situations where livelihoods options are limited or transactions drive the marriage process.

\section{Making space for} adolescents in livelihoods strategies for the poor

Jennefer Sebstad oriented the meeting by providing an overview of the rationale for working on adolescent livelihoods programs and outlining where initiatives fit into the theoretical and programmatic map of economic development.

Focusing on the economic dimension of adolescents' lives is crucial, because adolescence is the period when most people enter the work force. By ages 20-24, economic activity rates are often at their peak; in Bangladesh, for example, 68 percent of young people in this age group are involved in some form of economic activity; in Ethiopia, the comparable figure is 71 percent.

Many adolescents work not for extra income but from necessity. Adolescents' earnings are often essential to their households' survival as well as to their own individual survival should they be forced to leave their homes as a result of poverty or unsafe relationships.

Rather than any specific program activity, the livelihoods approach is a conceptual one that centers around the capabilities, assets, and activities required for gaining a means of living. Assets play both a protectional and a promotional role; they can smooth consumption when income is unsteady or emergencies occur, or they can function as a source to draw upon in order to take advantage of opportunities when they arise.

The livelihoods approach is suitable for working with adolescents because it is widely known and used; it encompasses both social and economic objectives; it is consistent with existing community-based approaches for adolescents; and it is relevant to all subgroups of adolescents, 
including those at the earliest stages of their economic lives.

Ms. Sebstad considered the range of services offered under current microfinance and microenterprise development schemes and speculated which might be most appropriate to adapt for adolescents. Microcredit is a financial service with some potential for older adolescents, but may be less appropriate for younger ones. Requiring a high level of discipline on the client's part to maintain timely and full repayments, microcredit works best where ongoing economic activity and sufficient household cash flow already exist. Adolescents often face regulatory barriers stipulating that a client must be 18 years or older in order to sign a microcredit contract.

Savings is, perhaps, the most relevant financial service for adolescents of all age groups. Helping young people to save can encourage them to develop and work toward future goals and can reduce their vulnerability by providing a cushion for future events or emergencies. Many young people already save informally, a finding that indicates an existing untapped capacity. Some adaptations may be necessary to make savings services successful with adolescents; services should allow for small deposits; be flexible, accessible, and fun; make policies and procedures simple to understand; and incorporate incentives for teaching discipline.

Microinsurance is a new and stilldeveloping service that may hold potential for adolescents. Exploring the usefulness of health and life insurance may have the additional benefit of giving policymakers and providers an entrée into discussions about adolescents' social issues (for example, the risks associated with pregnancy and childbirth that married adolescents face) and planning ahead for unforeseen events.

Social intermediation through nonfinancial services is of key importance in preparing adolescents for their economic lives as adults. Social intermediation can be defined as capacity building aimed at subgroups that lack access to productive resources. Covering such diverse topics as health education, group organizing, capacity building, literacy training, financial education (see Box 2), and skill building, social intermediation can be seen as laying the foundation for engaging adolescents in financial services and economic participation more generally.

Involving adolescents in various financial and nonfinancial services has been constrained by a number of misconceptions. Some believe that providing the young with opportunities to earn creates conflicts with schooling; others feel that subsidizing services for specific groups of disadvantaged people undermines market forces. Many adults grossly underestimate the strengths and capacities of adolescents to function as independent and responsible economic actors.

On balance, however, the outlook for adolescent livelihoods programming in the context of microfinance is promising. A paradigm shift that began in the late 1990s changed the focus from credit for enterprise development to financial ser- 


\section{Box 2 Financial education programs for adolescents: Principles and practices}

Kathleen Stack of Freedom from Hunger spoke about a livelihood-related activity with untapped potential for adolescents: financial education. Financial education is generally defined as teaching the knowledge, skills, and attitudes required for adopting good moneymanagement practices for earning, spending, saving, borrowing, and investing.

Ms. Stack proposed a planning model for designing a successful financial education program that begins with a concept and develops it into a detailed prototype to be tested. Although not specifically aimed at adolescents, the experience of the Self-Employed Women's Association (SEWA) in India in developing financial counseling services for its members was used as an example of the seven steps of planning. These steps are as follows:

1. Who: Identify who will be trained and tailor the training design to their needs and competencies. The financial counseling services were targeted at SEWA urban and periurban members: home-based workers, self-employed workers, a few wage earners, and some unemployed women. A significant number were slum-dwellers, and one-third were illiterate. The "who" also involved specifying the trainers for the activity, in this case, SEWA staff. Generally, staff members were young women with a high-school education who had some vocational training experience but limited knowledge of financial education.

2. Why: Define the purpose of the education. SEWA developed financial counseling services for bank members in order to build their capacity for establishing and meeting their financial goals, managing the risks of unexpected events, and making better use of SEWA services.

3 and 4. When and Where: Describe the timing, site, materials, and logistics required and available. With the learners and trainers identified, SEWA settled on appropriate times and locations for the lessons. Learning sessions took place once a week for six weeks for one to two hours during the day. The women met either at the SEWA bank office, at the home of one of the members, or at the SEWA neighborhood branch.

5. What: Delineate the content of the financial education. SEWA used quantitative and qualitative research methods to identify the members' current financial behaviors-positive and negative - and used these findings to identify desired future behaviors. Specific knowledge, skills, and attitudes related to these behaviors provided the basis for financial education activities.

For example, SEWA clients reported using loans rather than savings to meet immediate financial needs, which resulted in overindebtedness. They also reported spending money regularly on nonessential items, such as tobacco or movies. These current behaviors could be characterized as unwise or wasteful spending. The corresponding desired behavior could be saving instead of unwise spending, or developing and adhering to a savings plan. Educational content to promote these behaviors could include information about the benefits of savings, how to make savings plans, how to identify different savings options, and how to decide which option is most appropriate. 
6. What for: Establish the achievement-based objectives for the training. In a learning-centered approach, participants interact with the educational content and apply it in order to learn it. The educational content embodies achievement-based objectives that learners can accomplish and that trainers can observe during the training. SEWA expected that by the end of the training participants will have understood the benefits of starting to save early; defined their savings goals; assessed tradeoffs between savings and wasteful spending; made a savings plan; and compared savings options.

7. How: Describe the series of learning tasks and methods to be used. A final but critical step in designing a financial education program is to develop a series of learning tasks to accomplish the achievement-based objectives and to specify the teaching method or delivery system to be used. Effective teaching uses a dialogue approach; involves visual, auditory, and physical activity; is relevant and applicable to the learner; and occurs in a supportive and accepting environment.

vices for the poor, emphasizing demanddriven products and services and placing more attention on savings. Strategies for integrating nonfinancial and financial services are being refined, smoothing the transition between the two. Moreover, wide interest has grown in developing savings products and financial education for adolescents, creating a pool of committed partners and resources for experimenting with new programs and approaches.

\section{School and work transitions: Complemen- tarities and tradeoffs}

\section{Transitions to work in a changing global context: Implications of ris- ing rates of return to post-primary schooling}

Cynthia Lloyd of the Population Council opened the session on the complementarities and tradeoffs between work and school by presenting highlights from the National Academy of Sciences Panel Report Growing Up Global: The Changing Transitions to Adulthood in Developing Countries (published March 2005). The panel focused on the transition to multiple adult roles-worker, citizen, spouse/partner, and parent-describing six criteria for a successful transition:

- the best possible mental and physical health, including reproductive health, and the knowledge and means to sustain health during adulthood;

- an appropriate stock of human and social capital for becoming a productive adult member of society;

- the acquisition of social values and the ability to contribute to the collective well-being as citizen and community participant;

- adequate preparation for the assumption of adult social roles and obligations;

- the capability to make choices through the acquisition of a sense of 
self and a sense of personal compe-

tence; and

- a sense of general well-being.

Not coincidentally, these criteria correspond closely to the concerns inherent in the livelihoods approach.

In thinking about school and work in the development of adolescents into adults, Dr. Lloyd stressed the importance of new research on the development of the human brain showing that the brain is not fully formed until the middle teen years. Thus, experiences during this period are critical for the formation of certain reasoning and judgment capacities, and adolescents cannot be expected to act like adults nor to comprehend the full ramifications of their actions. School appears to function as a protective environment. For example, adolescents who are not in school are about two times more likely than those who are enrolled to be sexually active, but are only about half as likely to be using contraceptives if they are sexually active.

In considering schooling trends in subSaharan Africa, Dr. Lloyd noted an overall dramatic increase in school participation and attainment as well as a rapid narrowing of the gender gap in schooling (see Figure 1). The increase in primary-school completion rates has leveled off in recent decades, however, especially for boys, and remains steady at 58 percent. Another area of concern is the differential rates of school participation between the rich and the poor. This difference is greater among girls than boys and is greater among older adolescents (those aged 15-19) than among younger ones (aged 10-14).

In particular, three major trends for adolescents in the work force have been documented: the steady decline in childlabor rates with delays in labor-force entry; a marked rise in female labor-force

\section{Figure 1 Trends in primary-school completion rates by sex:}

Population-weighted regional averages for 24 African countries

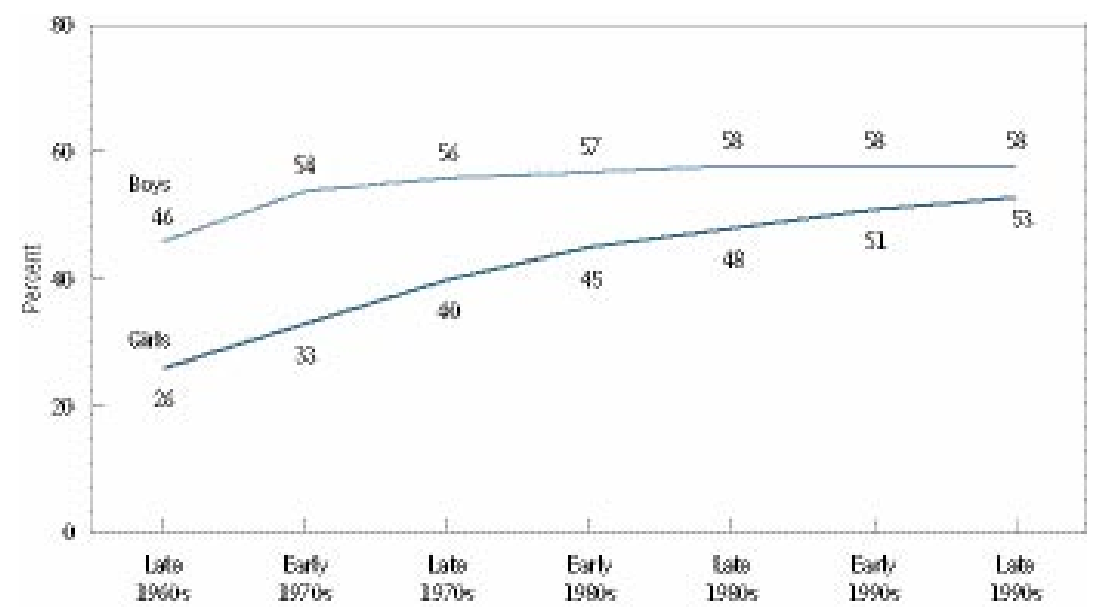


participation rates among those aged 20-24; and a rise in the proportion of the young labor force that is female.

Being both a student and a worker may pose conflicts for some adolescents. On one hand, a heavy domestic-work burden can compromise a girl's school attendance, and combining market work and schooling can compromise learning in primary school as well as a student's progression beyond the primary level. In some settings, however, working may allow adolescents to remain in school if they earn money for school fees that would otherwise not be available.

Certain measures can be taken to ease adolescents' work-school conflicts, such as adjusting the length and timing of the school day and making electric lighting available so that students can complete homework in the evenings. Potential ways of narrowing the poverty gap in enrollment include providing conditional grants or subsidies so that the poor can attend school, providing pathways back to school for those who have dropped out, and providing remedial help for students who need to combine work and schooling.

\section{Gender differences in time use among adolescents: The implica- tions of rising enrollment rates}

The dramatic increase in school enrollment for both sexes has significant implications for gender differences in time use. Amanda Ritchie and Monica Grant of the Population Council undertook an extensive review of the literature concerned with adolescents' time use and analyzed time-use survey data to investigate this relationship. The existing literature rarely disaggregated data by school enrollment, but some common findings on gender differences and work were evident. Notably, boys are more likely to perform wage work, whereas girls are largely confined to domestic work. Older students often combine work and schooling, and the total daily time devoted to work rises with age. Gender differences in time devoted to work exist regardless of age, with girls working more hours per day than boys.

Ms. Ritchie and Ms. Grant selected six data sets for in-depth analysis (from Guatemala, India, Kenya, Nicaragua, Pakistan, and South Africa) that surveyed adolescents ranging in age from 7 to 25 and collected information on school-enrollment status. For cross-country comparisons, analysis was limited to the 15-19-year-old cohort. Because time use is underreported when it is collected using a seven-day recall module, the researchers chose to use studies that relied on a 24-hour recall period. Students were asked about their activities on a school day, whereas nonstudents were asked about any weekday. Not surprisingly, nonstudents reported spending more hours than students on work; this finding holds true for both sexes and for both urban and rural areas.

Looking at mean hours spent in school and study on a school day, the researchers found little difference by sex or by urbanrural residence, but some difference among countries. For example, urban boys in South 
Africa spend 5.5 hours a day in school and study, compared with urban boys in India, who are similarly occupied for 8.9 hours.

Almost universally, girls work for more hours than boys regardless of schooling status (see Figure 2). In urban areas of Nicaragua, nonstudent girls work about one hour more per day than nonstudent boys ( 8.3 versus 7.2 hours), and female students work more than one hour longer per day than male students (3.2 versus 1.9 hours). When girls are in school, their domestic work burdens do not disappear: In some settings, female students spend as long as three hours a day performing domestic work.

Ms. Ritchie and Ms. Grant also investigated the association between leisure time and school enrollment. Although attending school decreases leisure time overall, they found that regardless of en- rollment status, boys enjoyed more leisure time than girls.

The researchers noted that although girls' work burden overall is greater than that of boys, female and male students spend their work time in similar ways. Nonstudents work longer hours than students, and their work is differentiated by sex. Increased emphasis on secondaryschool enrollment could allow this period of similarity to be extended, with possible implications for delayed or modified gender roles and socialization.

\section{The effect of paid work on schooling and pregnancy: Transitions to liveli- hoods in South Africa}

From this general perspective, a country-specific example was presented by Kelly Hallman of the Population Council,

\section{Figure 2 Mean hours spent on a school day by 15-19-year-olds in}

labor-market and noneconomic household work combined, selected countries

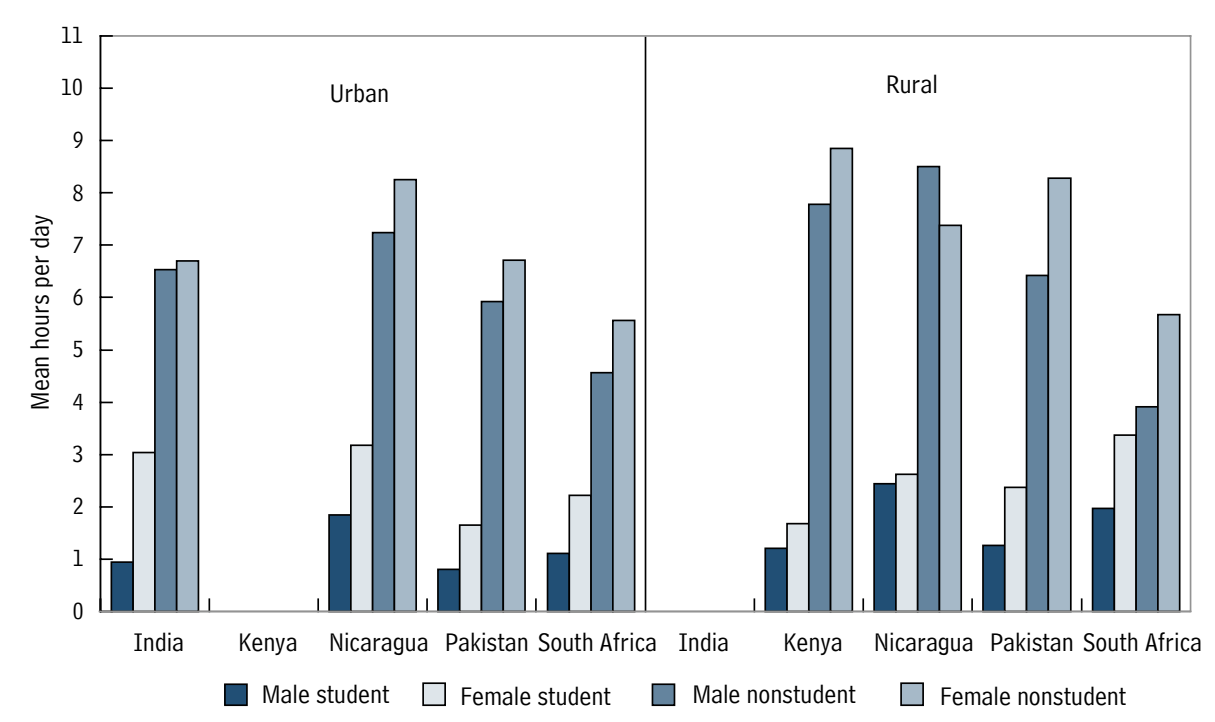


who described the effect of paid work on schooling and pregnancy in South Africa.

South Africa has one of the highest rates of educational attainment in subSaharan Africa, where high proportions of children enter school at an appropriate age, and boys and girls are largely comparable in the levels of schooling they attain. The main asset that the poor invest in is education. Despite this investment, literacy levels are relatively low for a middle-income country, and grade repetition is common; the 1999 National Household Survey found that half of the 20-year-olds surveyed were still in secondary school. The historical and current situation of economic and racial inequality, combined with the local financing of schools, causes schooling of uneven quality to persist, and that gap is widening.

Daunting obstacles exist for those attempting to enter the labor market in South Africa. As a result of the lasting effects of apartheid, many Africans lack the necessary human, physical, and financial assets to succeed, and few formal jobs exist in African communities. Moreover, the informal sector historically has been tightly regulated in South Africa and is consequently much smaller than that of other sub-Saharan countries. Additionally, the globalizing economy has translated into job losses for unskilled workers. In 1999, the official unemployment rate (a lowerbound measure of joblessness) stood at 23 percent nationally, 25 percent for black males, 35 percent for black females, and 42 percent for those between the ages of 15 and 24 (Statistics South Africa 2001).
To investigate the relationships between schooling, pregnancy, work, and economic status, Dr. Hallman analyzed data collected in 2001 from the survey entitled "Transitions to Adulthood in the Context of AIDS in South Africa." Some 4,000 young people aged 14-24 living in KwaZulu-Natal participated in the survey. Data were presented on household membership and wealth (divided into quintiles). Wide variations in wealth were evident both between and within races; approximately 30 percent of African households were in the two uppermost wealth quintiles, whereas 48 percent were in the two lowest quintiles. Households in the two lowest quintiles averaged less than one employed adult per household. The public grant to pensioners is a critical source of household income: It amounts to 700 Rand (US \$112) per month (the household poverty line in South Africa is 800 Rand per month). The availability of this grant influences the living arrangements of adolescents and whether they are able to attend school. All households, regardless of wealth, experienced relatively high levels of shocks (death, illness, or job loss) in the two years prior to the survey.

As expected, wealth has a strong effect on school enrollment whereby girls are more greatly affected than boys. Economic status has a dramatic impact on whether adolescents receive their matriculation certificate (awarded when the secondary level is completed). Thirteen percent of girls in the lowest wealth quintile, compared with 65 percent of girls in the highest quintile, received their 
certificate. School delays (dropping out during a school year or repeating a grade) are common among poorer adolescents; about two-thirds of boys and girls in the lowest quintile report ever having had to delay their schooling. A major reason that girls delay is pregnancy; more than half of the girls in the lowest wealth quintile were pregnant before age 20 .

Figure 3 summarizes the livelihood situations of young women aged 20-22, according to the assets they may be building, the financial strains they are balancing, and the income (or lack thereof) of household members. Extreme values are highlighted, and clearly reflect that women in the lowest wealth quintiles are the most vulnerable. Wealth has a strong effect on access to paid employment: The richest women are two times more likely than the poorest to have worked for pay in the past year. The high proportion of poor young women who have children is important because child-support grants of 160 Rand (\$26) per month are available for those who have children younger than 10 . Some researchers speculate that the existence of this grant may discourage some of the poorest girls from avoiding pregnancy.

In a comparison of female students who also worked for pay with those who did not work while in school, the former are found to have fared better across a number of domains: They were more likely to have matriculated, never to have had sex, to practice contraception if they were sexually active, never to have been pregnant, and to have many friends. Wealthier girls were more likely than poorer girls to combine work and school, however; thus these favorable outcomes are likely influenced by wealthier girls' increased access to resources.

\section{Discussion}

Discussion centered around the complex relationship between work and school for adolescents. One participant commented on mechanisms that attempt to push children into the school system by providing grants or subsidies to their families. A

Figure 3 Percentage of women aged 20-22, by livelihood situation, according to wealth quintile, South Africa, 2001

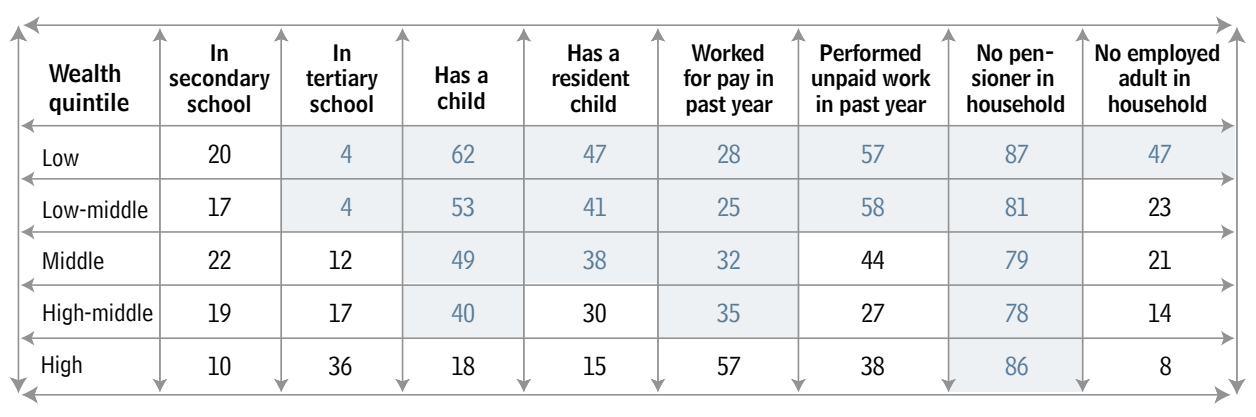

Source: Hallman and Grant (2004). 
study in Brazil that aims to eliminate child labor provides grants to parents whose children stay in school; parents sign a pledge that their children will not work, and children are required to attend afterschool programs so that they are occupied for the whole day. Although they refrained from suggesting that both initiatives are not needed, some participants debated whether emphasis should be placed on providing incentives to keep children in school, rather than supporting and developing adolescent livelihoods programs.

The point was made that informal education and learning is not well documented by existing studies and that these options may provide the flexibility required by those for whom working is a necessity. Informal education may be undertaken in the evenings or scheduled to accommodate the harvest, and it can be tailored to provide the skills that adolescents feel are most useful.

Several participants stressed the importance of considering the relationship between work and school in a contextspecific manner. Depending upon the length of the school day, labor-market options, the robustness of nongovernmental organizations' networks, and opinions of policymakers, among other factors, project objectives and approaches may differ dramatically. South Africa is a unique case, where public-assistance grants for pensioners and child support play an important role in the livelihoods strategies of economically disadvantaged families. Participants agreed, however, that regardless of the setting, the transition from school to work is not a well-planned one, and that schools could do more to prepare adolescents for their future as workers.

\section{The role of marriage in girls' livelihoods strategies}

\section{Marriage in the absence of alternative livelihoods options in Guatemala}

The presentations described below examined some of the ways in which marriage functions as a kind of livelihood strategy for girls in the absence of other options or social scripts. Jennifer Catino, Kelly Hallman, and Sara Peracca of the Population Council presented results from their work with indigenous girls in rural Guatemala. Guatemalans suffer from high levels of income inequality, especially between ethnicities: Indigenous Mayans are two times more likely than nonindigenous Ladinos to be poor. Decades of civil war have demolished the support systems within Mayan communities, where low educational attainment, early marriage, and early childbearing are the norm for girls.

In conducting secondary data analysis of the 2000 Living Standards Measurement Survey, the researchers found that Mayan girls were consistently more disadvantaged than Mayan boys and nonindigenous Ladina girls in a number of respects, particularly schooling. Mayan girls start school later and drop out earlier than their male Mayan and female non-Mayan counterparts. Between the ages of 12 and 14, school enrollment for Mayan girls drops sharply from 77 to 40 percent. Another 
large drop occurs between ages 15 and 16, from 33 to 19 percent (see Figure 4). Not only do Mayan girls drop out of school earlier than Ladina girls but also they are married earlier. Nearly two times more Mayan than Ladina girls aged 18-19 are married (43 percent versus 24 percent). Regardless of ethnicity, however, marriage is associated with low school attendance; almost no married girls are enrolled in school in Guatemala.

Mayan girls' livelihoods activities are strongly influenced by gender expectations and the restrictions and responsibilities that accompany marriage. In general, girls and young women carry the double burden of doing much of the housework as well as working in the fields and/or the family business (usually making and selling handicrafts). Unmarried girls are more than two times more likely than married girls to have worked for pay in the previous week (52 percent versus 24 percent). By con- trast, 83 percent of unmarried Mayan boys and 97 percent of married boys were paid for their work in the previous week.

To complement the quantitative analysis, the researchers conducted a qualitative study in four Mayan communities in the Guatemalan western highlands, consisting of focus-group discussions and indepth interviews (involving boys, girls, and parents), key-informant interviews (with teachers, employers, health-care service providers, and community leaders), and a community resource mapping. Although public education is "free" and mandatory through high school by law, this law is rarely enforced, and many indigenous rural families reported being unable to cover the costs of books, uniforms, and transportation. Girls face barriers to gaining an education that boys do not, such as security concerns, traveling distance to school, domestic responsibilities, and sociocultural values that prioritize boys' education.

\section{Figure 4 Guatemallan adolescents enrolled in school}

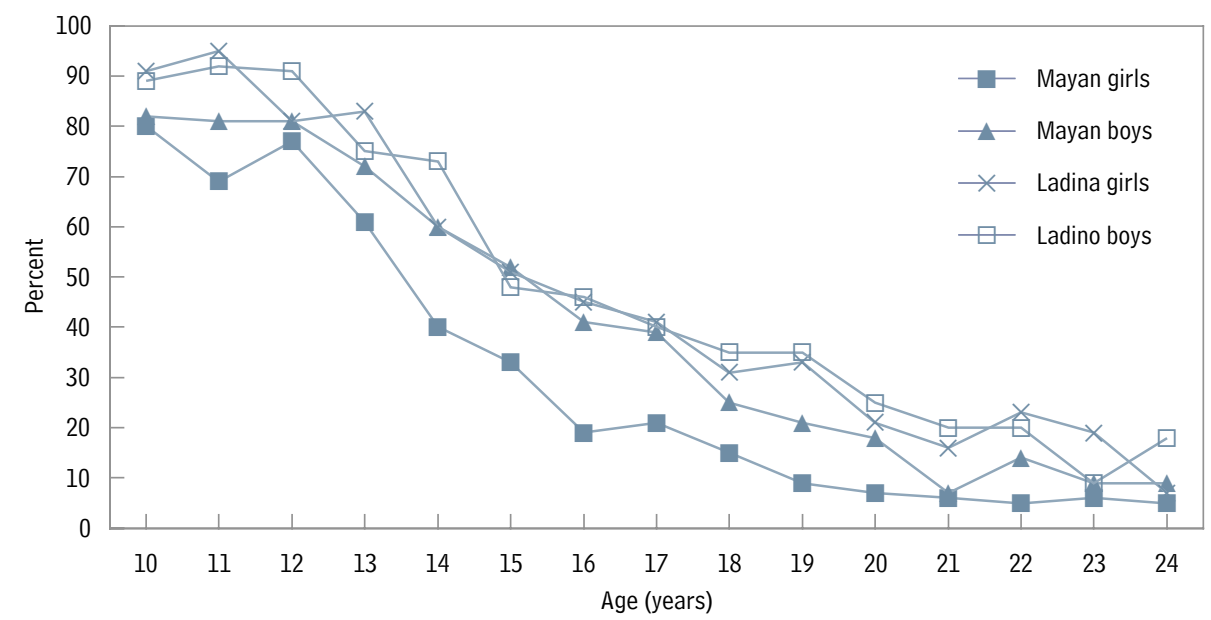


As one girl noted, "Some people tell my father, 'Don't support her studies because she won't do what you want; you'll only waste your money, and she'll get married and won't finish school.' "'

Puberty was identified as a major turning point, after which girls face mounting restrictions on autonomy, on social activities outside the home, and on their peer networks. Part of the motivation behind these limitations is parents' fear of premarital pregnancy. Although girls welcome opportunities to obtain paid work outside the home, their options are often limited. Early marriage is a socially acceptable and achievable means of leaving their natal home to gain a measure of autonomy. Girls expressed experiencing tremendous social pressure to marry at a young age and to conform to traditional gender roles; indeed, few could articulate future goals for themselves beyond marriage and motherhood.

Low educational attainment and strict gender roles severely constrain Mayan girls' livelihood options. Few vocational training options for girls, their low levels of fluency in Spanish, and an absence of role models and mentors cause Mayan girls to be poorly equipped with tools for earning a living. Moreover, the minority of working girls who are not relegated to unskilled jobs are paid far less than their male counterparts. In addition to these obstacles, other systems limit women's financial autonomy, such as inheritance and land-ownership policies that discriminate against women.

Confronted with barriers to staying in school, barriers to finding and keeping paid work, and structures that reinforce economic and social dependence on men, it is hardly surprising that Mayan girls marry young. In the next phase of this project, the researchers aim to broaden the choices for and build the assets of Mayan girls by focusing on six main areas: strengthening social networks; exposing girls to positive role models and mentors; improving basic skills and opportunities for employment; planning for life-cycle events; teaching basic money-management skills and entrepreneurship; and providing sexual and reproductive health information and links to services.

\section{The role of economic considerations in the timing of marriage: Contrasting situations in Bangladesh and Egypt}

Sajeda Amin of the Population Council examined the role of marriage transactions in Bangladesh and Egypt. Although the form and nature of marriage transactions differ greatly in these two countries, nevertheless, they have profound implications for the timing of marriage.

In Bangladesh, early marriage is pervasive in rural areas, where the vast majority of the population resides. Both early marriage and rising dowry demands undermine the status of rural adolescent girls. In her earlier work, Dr. Amin documented how secondary-school scholarships can keep rural girls in school and how employment in the garment manufacturing industry can delay marriage and allow girls to negotiate a measure of autonomy as a result of their earning potential. Building on the lessons learned 
from these projects, Dr. Amin sought to explore how livelihoods opportunities could be enhanced within rural areas to reduce the necessity of migrating for work and how the social benefits of work could be maximized.

In partnership with BRAC (formerly the Bangladesh Rural Advancement Committee), the Center for Mass Education in Science, the Bangladesh Institute of Development Studies, UNICEF Dhaka, and the Ministry of Women and Children Affairs, Dr. Amin developed a three-year program of intervention and research (2001-04) that aimed to empower rural adolescent girls through expanding community, peer, and social networks, and through helping them acquire livelihoods skills and life skills, including reproductive health education. Groups of about 20-25 girls met weekly in "reading centers," where peer educators provided skills training and led group activities and discussions. Members were given opportunities to participate in savings groups, identify and design livelihoods projects, and receive credit and training. The project benefited from the communities' familiarity with adult microcredit programs, and parents were, therefore, more open to permitting the girls and young women to participate than they might have been otherwise.

A baseline survey was conducted with 5,100 boys and girls aged $13-22$ who were randomly selected from 75 intervention and 15 control villages. Major findings included a diminishing gender gap in education favoring girls; a high prevalence of early marriage (although significant variation existed between districts with mean ages at marriage ranging from 16 to 18 years); early school drop-out for girls as a consequence of marriage; and limited mobility and social networks for girls

Partly because of their widespread prevalence, dowry practices were examined in-depth. In the study villages, three out of four marriages involved an exchange of dowry. Dowry costs can be lowered by marrying off a daughter at a young age or by other strategies, such as managing her reputation. Although economic status and educational attainment did not affect the size of dowry demands greatly, age at marriage was found to have a consistent effect. Dr. Amin estimated that, on average, a family might spend about 1,000 takas ${ }^{1}$ more in dowry for every year of delay in the bride's age at marriage. As the program continues to be evaluated, attention will center on how new livelihood opportunities affect dowry costs and marriage age, and whether or not changes in educational attainment and marriage age can be attributed to the intervention.

Dr. Amin also examined the economics of marriage in Egypt, where marriage transactions are also deeply entrenched. An important contrast between Egypt and Bangladesh is the direction of payments and the beneficiaries of the payments. Whereas in Bangladesh the burden of payment falls entirely on the bride's family, in Egypt the bride and groom share payment but the groom contributes more than the bride. In Bangladesh, the married couple

${ }^{1}$ In 2004, 60 takas $=$ US $\$ 1$. 
are not always the ultimate recipients of the dowry; in fact, the extended family of the groom commonly seizes control of the dowry. In Egypt, the costs incurred at marriage are mostly those involved in setting up a separate household for the couple.

To explore young working women's perceptions of marriage and work in Egypt, 27 case studies were conducted of girls aged 15-25 who hold jobs in garment manufacturing, in sales and services, or in small factories. ${ }^{2}$ Respondents were drawn from three locations in northern Egypt: Port Said investment zone on the coast, the periurban community of Ain Helwan near Cairo, and rural Bedeen village in Mansoura District.

Although marriage in Egypt is typically a matter of family negotiation regarding choice of partner and timing of the wedding, working women often are actively involved in the process of searching for a spouse and exercise some control over the decision in direct and indirect ways. Young couples are increasingly likely to aspire to live in their own households after marriage rather than with the extended family and to have high expectations in terms of marital living standards, as trade liberalization feeds a growing consumerism.

The length of the engagement period has increased, partly as a consequence of the rising costs of marriage. Huge financial transactions occur at the time of the wedding, often the equivalent of several times the yearly household budget. Sing-

2 This section draws substantially on the project report by Amin and Al-Bassusi (2003). erman and Ibrahim (2001) estimate the mean cost of a marriage transaction to be around 20,000 £E (US $\$ 3,470)$. Both bride and groom contribute to the expenses of setting up their new household; assets are explicitly listed at the time a marriage is contracted. Generally, the groom provides housing and major items of furniture, while the bride brings the china, kitchen appliances, and utensils.

The great majority of young women who participated in the survey reported that a primary reason they took a job was to prepare for marriage and contribute to their gehaz (trousseau). To this end, they save as much of their income as possible. Aisha, for example, reported using $45 £ E$ (\$8) a month for transportation and saving the rest of her salary for her gehaz, so that her marriage will be less of a burden for her parents. Girls' contributions can be substantial: Amaal worked in a factory and contributed $3,000 £ E$ of the $8,000 £ E$ (\$510-1,360) needed for her gehaz. In addition to working, girls and their families develop other strategies to raise money such as borrowing, migrating for better jobs, and joining rotating savings groups (gemayyah).

Survey participants gave a range of reasons for the importance of the gehaz, including considerations of the bride's family's social status, the need to conform to the values of the community, and the desire to enhance the status and wellbeing of the bride with her in-laws. As one girl commented, "In order to keep my dignity, I have to prepare myself as well as I can. The cupboard of the dining room has 
to be full of china that I will never use, but I cannot keep my head above my shoulders if I do not buy it."

Some commented on the tradeoff between education and work because of the pressure to marry. One young woman reflected,

If I went to an institute [of higher education], I would want to marry a man with at least the same degree, if not a higher one, and it would be more costly for my family to prepare me for marriage. First, I would not have enough time to work before marriage to help myself, and also a groom with higher education and status would want a more costly gehaz from my family.

Although having had some education was seen as yielding "returns" in the marriage market (for example, many see education as a key element to being a good mother), having a higher education might actually lower a girl's marriage prospects.

Dr. Amin concluded that in Egypt, wage work reinforces rather than challenges gender norms and expectations of roles within marriage: Young women's work is viewed as a temporary phase of their lives (women are expected to stop working after they marry) and as necessary for contributing to their gehaz. In contrast, livelihoods opportunities in Bangladesh potentially have a modernizing influence on traditional values and allow girls to gain new decisionmaking abilities. Both studies, however, highlight how economic factors play a central role in decisions about the timing of marriage and should be taken into consideration when developing policies and programs to improve the lives of adolescent girls.

\section{Marriage and livelihoods strategies in post-Doi Moi Vietnam}

Sara Peracca of the Population Council provided another viewpoint of the interplay between marriage and livelihoods strategies drawn from her work in Vietnam. Beginning in 1986, the Vietnamese government slowly began embracing free-market ideas, ushering in an era of economic liberalization and greater integration with global markets (known as doi moi, or the reconstruction period). Dr. Peracca and Dr. Amin collaborated with colleagues at the Hanoi Institute of Sociology to investigate the influence the gendered response to these increased opportunities.

A review of the literature suggests that following increased economic opportunities a gendered response typically occurs. Specifically, women work longer hours than men, agriculture becomes feminized, and men's lesser contributions to domestic work do not change. To understand the response within Vietnam, Dr. Peracca and her colleagues analyzed the 1992 and 1998 Vietnam Living Standard Measurement Surveys (VLSS), nationally representative surveys of 4,800 and 6,000 households, respectively. They augmented this analysis with a small-scale in-depth study whereby time-use data and life-history matrices were collected together 
with data from open-ended interviews and focus-group discussions. The study was conducted in four communes, two in the north and two in the south. One commune in each region represented a high-opportunity setting (Gia Lam and Dong Nai), and the other two represented low-opportunity settings (Hung Yen and Ben Tre).

Analysis of the VLSS data showed that both men and women are marrying at later ages. Forty-three percent of women aged 15-29 in 1992 reported being married, compared with 31 percent in 1998. As new opportunities arise, young people are no longer finding marriage to be the sole livelihood strategy available to them. The commune studies found that young Vietnamese women generally feel that if they do poorly at school, they will find some type of work; they do not report that they will look for a spouse. As a 17-yearold woman from a low-opportunity area in the south remarked, "If I fail in my studies, I will learn how to sew and apply for a job in some company."

While work-force participation of unmarried young people decreased between 1992 and 1998 (largely as a result of increased school enrollment), the proportion of young married people who entered the work force increased (see Table 2). Unmarried young women experienced a slight increase in paid employment, a finding similar to the recent experiences of other developing countries. Although many slight changes have occurred in la-

Table 2 Percentage of survey respondents, by age group and type of work, according to sex, marital status, and survey year, Vietnam

\begin{tabular}{|c|c|c|c|c|c|c|c|c|}
\hline \multirow[b]{3}{*}{ Characteristic } & \multicolumn{4}{|c|}{ Men } & \multicolumn{4}{|c|}{ Women } \\
\hline & \multicolumn{2}{|c|}{ Unmarried } & \multicolumn{2}{|c|}{ Married } & \multicolumn{2}{|c|}{ Unmarried } & \multicolumn{2}{|c|}{ Married } \\
\hline & 1992 & 1998 & 1992 & 1998 & 1992 & 1998 & 1992 & 1998 \\
\hline \multicolumn{9}{|l|}{ Age $15-29$} \\
\hline (N) & $(2,149)$ & $(3,036)$ & (956) & $(790)$ & $(1,925)$ & $(2,609)$ & $(1,384)$ & $(1,169)$ \\
\hline Overall LFP & 75 & 66 & 91 & 95 & 78 & 67 & 77 & 81 \\
\hline \multicolumn{9}{|l|}{$\begin{array}{l}\text { Type of work (among } \\
\text { those in labor force) }\end{array}$} \\
\hline Agriculture & 68 & 61 & 73 & 64 & 63 & 58 & 77 & 72 \\
\hline $\begin{array}{l}\text { Manufacturing/ } \\
\text { commerce }\end{array}$ & 19 & 31 & 11 & 30 & 28 & 35 & 16 & 23 \\
\hline \multicolumn{9}{|l|}{ Age $30+$} \\
\hline (N) & (270) & (482) & $(3,549)$ & $(4,845)$ & $(1,289)$ & $(1,834)$ & $(3,330)$ & $(4,609)$ \\
\hline Overall LFP & 53 & 56 & 83 & 84 & 56 & 55 & 79 & 83 \\
\hline \multicolumn{9}{|l|}{$\begin{array}{l}\text { Type of work (among } \\
\text { those in labor force) }\end{array}$} \\
\hline Agriculture & 54 & 45 & 67 & 60 & 67 & 57 & 68 & 64 \\
\hline $\begin{array}{l}\text { Manufacturing/ } \\
\text { commerce }\end{array}$ & 17 & 42 & 15 & 28 & 25 & 34 & 21 & 29 \\
\hline
\end{tabular}

LFP $=$ Labor-force participation. 
bor-sector involvement by gender and age group, the most dramatic change is the overall decrease in the proportion of those working in agriculture and the increased number of those with jobs in manufacturing and commerce. The proportion working in agriculture declined the least for married women older than 30 , reflecting the increasing feminization of agriculture in Vietnam.

Time-use data revealed that, across all ages, women have significantly less leisure time than men. Much of this disparity was attributable to an unequal domestic work burden; girls and women reported spending more than three times the amount of time on domestic work than boys and men reported. Interestingly, a relatively high proportion of married men reported performing domestic work. These tended to be men who were relatively well-educated, who did not work in agriculture, and whose wives did not work in agriculture. Even with this help, however, married women who are working still have considerable domestic duties, so that, in effect, they shoulder a double burden.

Higher educational attainment and expanded wage-work opportunities have enabled young women to delay marriage in order to enjoy this transitional period of autonomy. As one 20-year-old woman explained, "I don't want to get married because then I will lose my freedom and have to care for my husband, my in-laws, and my parents. But if something happens, it happens. I plan to marry after I have finished my studies and have worked."

\section{Discussion}

The majority of the discussion revolved around the pervasiveness of dowry transactions and its implications for brides. One participant noted that since dowry exchanges have been banned in Bangladesh since 1985, the practice has gone underground; marriage contracts are not explicit about the transactions that take place. The connections between dowry demands and domestic violence were discussed. If accounts are not settled by the wedding day, parents express concern that their daughter will face poor treatment in her new home. Interestingly, a study was mentioned that found that brides who paid a dowry are more likely than those who did not pay one to report domestic violence. Moreover, respondents who paid small dowries report much higher levels of abuse than do those who paid large dowries.

Another participant observed that the global increase in girls' educational attainment could be due partly to the perceived value of education in the marriage market. Because the selection of a spouse has implications for a family's future economic security, better-educated girls are increasingly considered to be more desirable mates.

In light of how deeply entrenched dowry transactions are in Bangladeshi culture, some participants speculated whether it might be more feasible to alter the meaning of the practice than to attempt to eliminate it. For example, the dowry could be regarded as insurance money, to be returned to the girl if her husband decided to end the marriage. 


\section{The social dimensions of livelihoods programming for adolescent girls}

\section{Box 3 The Population Council's portfolio of research concerning adolescents: $\mathbf{A}$ global overview}

Since the early 1990s, the Population Council has been involved in expanding the field of policy research on adolescents from one that is narrowly focused on sexuality and reproductive health and behavior to the broader social and economic issues that underpin adolescents' health.

The Council has developed a strong portfolio of projects designed to elucidate the forces that shape adolescents' lives and to identify, design, and test various interventions to expand opportunities and reduce the social and economic vulnerabilities of adolescents, particularly girls. Judy Diers and Judith Bruce presented an overview of the current portfolio (from which several projects are discussed in greater detail below), and highlighted some of the main observations and lessons learned from this diverse body of work.

The 12 projects in the Council's portfolio on adolescents cover a wide geographical area, ${ }^{3}$ generally in settings characterized by early (often involuntary) marriage, high fertility, and an HIV epidemic selective of young women. These projects target a broad range of subgroups; some interventions work only with unmarried girls, others only with married girls; some, like one in Egypt, focus on out-of-school girls; others, like one in Kenya, involve both boys and girls. Program participants range in age from 10 to 24, depending upon which transitions are the focus of the program (puberty, school-leaving, marriage, childbearing, and so forth).

\section{Several observations and lessons were shared:}

1. Adolescent girls should be grouped into salient social categories for effective livelihoods (or other development) work. Working with unmarried adolescent girls requires a sensitivity to community norms concerning marriage to ensure that the activities, mentors, and program content will not threaten parents' perceptions of their daughters' marriageability or respectability. Reaching married adolescent girls with social, development, and livelihoods activities and with health information and services requires negotiating spouses' control over young brides and grappling with the girls' increased burden of domestic work and reduced social mobility. For example, in rural Burkina Faso, program staff worked in pairs so that one outreach worker could talk with a married girl in her home while the other engaged family members' attention, thereby creating a "space" for the girl.

(continued next page)

${ }^{3}$ Projects are situated in Bangladesh, Burkina Faso, Egypt, Ethiopia, Guatemala, India, Kenya, Mali, and Pakistan. 
2. More research must be conducted on how to use group experiences optimally to achieve projects' objectives. The eight Council projects that were in the intervention phase all involved the formation of groups that met in designated "safe spaces." Dr. Diers raised the question of how much (and what kind of) exposure is sufficient to achieve the project's objectives with this age group, be they social objectives (such as creation of new social spaces or establishment of nonfamilial social networks) or nonsocial ones (such as helping adolescents acquire reproductive health information or open a savings account). Some groups met intensively for a short period of time (24 hours a week for four months), whereas others met for 12 hours a week for two years. Is one model more effective than the other in producing long-term outcomes? In addition to the "dose effect," what other programmatic variables affect program quality? These are the types of questions that the second generation of programming should address.

3. Girls are eager and able to save money, but several obstacles to such efforts remain. In addition to the enhancement of social networks, many of the projects actively promoted savings schemes for adolescent girls, either at an individual level (for example, postoffice accounts in India), or at a group level (such as the mandatory savings linked to group-based credit in Kenya or the informal savings clubs, gamayas, in Egypt). In general, researchers found that the demand and capacity for saving is high among adolescents. Indeed, before the projects began, many girls already had saved informally both individually and in groups.

Obstacles to adolescents' savings efforts that were sometimes encountered included discriminatory attitudes of institutional staff and prohibitive minimum-age requirements for opening accounts. Ms. Bruce noted inconsistencies in many settings where the minimum legal age for work is lower than the minimum age at which banking is allowed, and suggested that these regulations should be aligned. Adding economic elements such as savings schemes to programs makes them more attractive both to girls and to their families, who may be more willing to let their daughters participate if they anticipate economic benefits from program activities. Allowing girls to have control over and access to their savings is critical; locking their money away from them can, in fact, increase their risk and vulnerability.

For programs to reach and retain adolescent girls' participation, program information, features, and approaches must be adapted to suit their unique needs and situations. Some girls' social isolation and lack of contact with peers, mentors, and role models cause them to be attracted to programs for their social dimensions as much as for their substantive content.
Of the five projects described in this section, some are primarily livelihoods interventions, whereas others are reproductive health programs that incorporate livelihoods activities. Yet all of them explicitly address the social disadvantages that adolescent girls face. These disadvantages vary widely, depending upon circumstances, such as whether the girl is mar- 
ried, living in an urban slum, out of school, or living in a refugee camp. Some projects aim to strengthen girls' social networks so that they can draw on peer-group relationships for support; others conduct activities with gatekeepers to discuss how certain social norms are harmful to girls. Girls' social disadvantages are important to remedy in their own right, and they must be reduced if girls are to benefit fully from other program components.

\section{Addressing the social context of married adolescent girls: Experi- ences from the First Time Parents Project, India}

Nicole Haberland and K.G. Santhya presented findings from their work in India to reduce the social and health disadvantage of married girls. Although age at marriage is increasing in India (as it is globally), early marriage continues to affect substantial numbers of girls. Nationwide, 24 percent of 20-24-year-old girls are married by the age of 15 , and 50 percent are married by 18. Overwhelmingly, sexual activity among adolescent girls in India takes place within the context of marriage. Obviously, however, this socially sanctioned institution does not inherently make sex safe, voluntary, or pleasurable. Several studies document that girls characterize early sexual encounters within marriage as frightening and nonconsensual. Facing intense pressure to have a child, married girls may become pregnant before they are physically ready or able to access the resources they need to have a safe delivery. Young first-time mothers are more vulner- able than older, parous women to preeclampsia, obstructed labor, and fistula.

Although the needs of married girls are great, little is known about their lives, and little has been done to support them. This neglect may be due to assumptions that married girls have the same access to health-care services and support as married women or that the elevated social status of being married renders them less vulnerable than unmarried girls. Yet the limited mobility and autonomy and social isolation of married girls are likely to make their sexual and reproductive health needs distinct from those of married women or unmarried adolescent girls.

The Population Council, together with the Child in Need Institute, the Deepak Charitable Trust, and the International Institute for Population Sciences, is currently implementing the First Time Parents Project as an important step toward meeting the unique needs of this group. The project's goals are to develop and test an integrated package of social and health interventions that would improve married adolescent girls' reproductive and sexual health knowledge and practices and increase their ability to act in their own interest. The researchers posited that the transitional period around marriage and the first pregnancy and birth could serve as a powerful entry point to improve the knowledge and behavior of married girls and their partners.

Implemented in 24 rural villages surrounding the cities of Vadodara (Gujarat) and Diamond Harbour (West Bengal), the project is comprised of three main compo- 
nents: information provision, facilitation of health-care-service use, and groupformation and social networking activities. The group activities, in particular, are key factors in ameliorating the social vulnerabilities and isolation that married girls face. Baseline data found that married girls' mobility is restricted (only 5 percent of girls in Gujarat are allowed to go unaccompanied to the post office), that they are junior partners in decisionmaking in their homes, and that their peer networks are limited (only 7 percent of girls in West Bengal reported having friends in their marital home).

The aim of the groups is to increase married girls' contact with peers and mentors, expose them to new ideas, and help them learn how to identify issues that affect them and to act on them. The project has mobilized more than 750 girls gathered into groups of about 8 to 12 girls each. The groups typically meet for two hours on a bimonthly basis in venues such as youth clubs, schools, or members' houses. Ideas for topics and activities are identified by the girls themselves, and range from legal literacy, to vocational skills, to pregnancy and postpartum care. In addition to the bimonthly meetings, exposure visits are conducted to village administrative offices, banks, post offices, and women's organizations.

The researchers were well aware that ensuring married girls' participation in the project required special effort, and they tailored the intervention to match the girls' workload and limited mobility, an important consideration to keep in mind in planning livelihoods programs for married girls. Community organizers and female health workers conducted home visits to talk about group membership not only with the targeted beneficiaries but also with mothers-in-law. In situations where a husband objected to his wife's participation, community organizers enlisted the help of male health workers or sympathetic mothers-in-law or sisters-in-law to persuade him. Group meetings are usually held in the afternoon so that members can complete their household chores prior to attending. Membership is flexible: New members can join at any time, and current members can attend as their schedule permits. This flexibility is critical in light of the customary movement of young women back to their natal homes to give birth and to recuperate postpartum, especially for the first birth.

Although they are not specifically excluded, married adolescent girls may not be reached by community-based livelihoods and social mobilization programs. The experience of the First Time Parents Project thus far shows that the social isolation and disadvantages faced by married girls may be mitigated with efforts that are aimed at building up social networks and at seeking support from the girls' husbands, mothers-in-law, and other influential family members.

\section{Understanding the lives of unmarried adolescent girls in a rural setting in India: Lessons for livelihoods interventions}

Shveta Kalyanwala and Mary Philip Sebastian from the Population Council's New 
Delhi office presented results from their work with unmarried girls in rural Gujarat. Specifically, the researchers sought to explore the extent to which participation in livelihoods activities develops skills that facilitate future income and employment opportunities, enhances abilities to exercise autonomy and negotiate a better future, and strengthens and expands social networks.

In partnership with the Self-Employed Women's Association (SEWA), the researchers implemented their project in ten villages with girls aged 13-19. A baseline survey conducted in 2002 confirmed that irrespective of sociocultural setting, girls' capabilities and life choices were limited on multiple levels. Although some girls were able to travel within their neighborhoods unescorted, only 15 percent were able to go outside their neighborhood to a health-care facility and 11 percent were allowed to visit a relative or friend unescorted. About one in four girls was performing wage work at the time of the survey; however, few had control over their earnings. The vast majority (91 percent) handed their wages over to their parents. Girls generally lacked confidence in their communication skills; only 20 percent felt they could express their ideas to others.

Against this background, kishori mandals (youth groups) were formed in each village, with 15 to 30 members in each mandal. These peer groups met three to four times a week for two hours at the sahayika's (group leader's) home. Activities typically included singing, sports and games, discussion of articles in Akash
Ganga (a magazine written by and for adolescents), and literacy lessons. "Awareness-building" sessions were held, in which group leaders or SEWA staff would discuss topics including health, nutrition, agriculture, water management, and savings, or the group would make exposure visits to a bank, historical monuments, or the local milk cooperative.

A number of vocational courses were offered, ranging from the traditional (tailoring, embroidery, food preservation) to the nontraditional (computer training, hospital assistant, equipment repair). After overcoming their initial hesitation, and encouraged by project staff, the girls and their parents came to accept the nontraditional courses. The new skills learned in these courses potentially have longerterm benefits in terms of changing gender norms and opening up new avenues for future income and employment. Two hundred and eighteen girls took advantage of at least one course. Some of the training sessions were held in towns, broadening the students' exposure to the outside world.

Reflecting upon the project, Ms. Kalyanwala and Ms. Sebastian noted that the girls valued the groups (their attendance was regular and sustained) as a legitimate safe space that gave them time to interact with their peers. During the 18 months that the groups met, the girls developed strong bonds and discussed strategies for helping members who were having problems.

The girls have demonstrated their improved ability to talk in front of groups; some even report sharing their knowledge about agriculture with their communities. 
They also feel better prepared to handle new experiences, whether it be negotiating the public transportation system or attending an overnight training session in an unfamiliar place. Importantly, the girls have developed a greater awareness of the services that exist in the community and of their right to obtain access to such services. A consideration for future programs is to place greater emphasis on savings schemes. Girls expressed a strong desire to save and to have greater control of their resources. Follow-up research should be conducted in order to assess whether these short-term changes in knowledge and behavior develop into longer-term changes in developing positive savings behaviors, building assets, and taking advantage of work opportunities.

\section{Integrating sports, literacy, and life skills for out-of-school adolescent girls in rural Egypt}

Alyce Abdalla from the Population Council's Cairo office presented the achievements of the Ishraq (enlightenment) project using a social-capital framework. ${ }^{4}$ Group-forming activities and network cre- ation are two mechanisms that can build social capital. At the individual level, theory suggests that social capital enhances content acquisition, supports the application of learning, and boosts self-confidence and agency ${ }^{5}$ so that participants can increasingly act on their own behalf and take advantage of opportunities that arise. In traditional settings where family and community are particularly important in defining choices, group creation and support can be critical to changing girls' lives.

In collaboration with Save the Children, Caritas, and Centre for Development and Population Activities, and in consultation with the Ministries of Youth, Education, and Health, the Ishraq project was designed to boost the social capital of participants. Implemented in four villages in the El Minya governorate of Egypt, rural out-of-school girls aged $13-15$ were exposed to an integrated curriculum consisting of literacy, life skills, and sports components. Activities were also designed for adolescent boys and for the parents of participants.

Group formation was a critical part of Ishraq's success in building social capital. Groups of about 25 girls met four

\footnotetext{
${ }^{4}$ According to Putnam (2000), social capital refers to the collective value of all "social networks" [who people know] and the inclinations that arise from these networks to do things for each other ["norms of reciprocity"]. The central premise of social capital is that social networks have value and that a wide variety of specific benefits flow from the trust, reciprocity, information, and cooperation associated with these networks. Social capital creates value for the people who are connected and, at least sometimes, for others as well.

5 "Agency" has been defined variously by different constituencies, but generally refers to the ability to define one's goals and act to accomplish them. Kabeer (2001: 21) states that more than observable action, agency encompasses "the meaning, motivation and purpose which individuals bring to their activity, their sense of agency, or 'the power within'." Agency incorporates a wide range of purposive actions including bargaining, negotiation, manipulation, and protest, as well as the more intangible cognitive processes of reflection and analysis.
} 
times a week for two and a half years in local schools or youth centers. This intense, sustained interaction helped create strong, cohesive groups. The program was such a novelty, and so unheard of, that group identity was strengthened as the girls became famous, not only in their communities, but beyond (people from Cairo and even from abroad visited Ishraq groups frequently). The Ishraq girls not only saw themselves as a group but also were recognized as such by outsiders. Extensive networks were created, not only with their peers but also with nongovernmental organizations, government ministries, and others. For these rural girls, many of whom had never before left their villages, this broadening of perspective was eye-opening.

In part as a result of group solidarity and the feeling of being part of something special, the girls were highly motivated to learn. One of the program's goals was to move participants back into formal schooling; 92 percent of the Ishraq girls passed the government literacy exam (compared with a national passing rate of 75 percent), and a significant number of the girls enrolled in formal preparatory schools.

The girls have proved adept at making use of the relationships they have made with other organizations. The girls who passed the literacy exam were initially told that they would have to wait two years to receive their certificates, by which point most of the girls would probably be married and unable to continue their schooling. Outraged, they contacted the relevant authorities though their connections with
Save the Children, made their case, and received their certificates within two months.

The Ishraq girls have shown that they can handle new situations and act on their own behalf. For instance, when a disapproving community member shut down the transport that was to deliver them to training in hairdressing and wedding preparation, one girl contacted her teacher and made separate arrangements. This girl subsequently opened her own salon.

Ms. Abdalla argued that greater attention should be paid to the intricacies of group formation and network building. Much of the literature that exists on these topics is based on a Western model of using groups and teams to boost productivity in the corporate world. In the developing world, linkages need to be formed more deliberately and thoughtfully so that they are sustainable, whether they be mentoring relationships with community members or partnerships with organizations.

\section{Integrating social support into microcredit programs for adolescents: The experience of $K$-Rep's group-mentoring scheme}

On behalf of Arjmand Banu Khan (of the Population Council's Nairobi office), Annabel Erulkar discussed a microfinance and mentoring program for adolescents in Kenya. The Tap and Reposition Youth project (TRY) is a collaboration between the K-Rep Development Agency (KDA), the implementing agency for the project, and the Population Council, which provides technical assistance and conducts research. 
The TRY project targets out-of-school young women and men aged 16-22 in lowincome and slum areas of Nairobi and uses an integrated approach combining credit, savings, and training in business management and life skills. Phase I of the project took place from 1998 to 2000. It explored the feasibility of a group-based lending program for adolescents, who are generally viewed as "risky borrowers." Important lessons were gleaned from Phase I: A high demand for credit and savings exists among adolescents, and girls-only solidarity groups provide its members with a vital source of social support that is otherwise lacking in their lives. Project experience further showed that microcredit programs can have significant noneconomic benefits, such as establishing safe spaces for young people, improving girls' ability to make life choices, and increasing girls' knowledge of reproductive health issues.

The researchers noted that the credit officer played a critical role in Phase I: When she was absent for an extended period of time, repayment rates dropped. The girls had begun to rely on her for advice about personal issues as well as about business and money-management concerns. However, the credit officer had not been trained to handle the complex social problems that sometimes compromised the girls' participation in the credit activities (for example, unwanted pregnancy, abusive relationships, and lack of shelter).

Although some of the girls did well in terms of group participation, credit management, and timely repayment of their loans, others were less prepared for the responsibilities and obligations associated with group-based credit. Assessment of the project at the end of Phase I suggested that offering credit to more mature adolescents was appropriate, whereas group meetings and savings schemes were appropriate for a broader spectrum of adolescents.

Therefore, when preparations were made for scaling up the TRY project in Phase II, plans were included to introduce group-based mentoring. The mentors are women and men aged 29-50 drawn from several professions, including counseling, social work, business, health care, and community development. Each mentor is assigned two or three groups with whom they meet on a weekly basis following the savings and credit meetings. Considered to be part-time staff, the mentors are paid a stipend for their work.

Mentoring activities include:

- needs assessments for TRY participants;

- group discussions and activities;

- educational seminars;

- one-on-one counseling;

- referrals to other services;

- monthly meetings with project managers; and

- record keeping.

Although participation in the mentoring sessions is voluntary, the sessions are well attended and the girls have responded enthusiastically.

\footnotetext{
This program is very good, even more than the loan... . There is nothing as good as advice. ... You
} 
could be having a problem, and you

don't know who should help you,

but when you get someone to dis-

cuss it with, you feel good.

She [the mentor] is like a mother

figure, and she advises us on life

issues, relationships, and how to

cope with crisis situations in life,

[such as problems we have] with

our boyfriends and husbands.

Ms. Khan felt that although the mentoring program was successful, it could be improved by having mentors visit participants' homes and businesses, by covering a wider range of topics during sessions, and by training mentors in management of self-help groups and in participatory facilitation skills. Retaining mentors is a challenge; several have left the program. Another challenge is blending the differing institutional cultures that provide financial services and social support. Strengthening the capacity of KDA staff to provide social support for these girls (and boys) requires special effort.

To summarize, mentoring through microfinance groups can be an effective strategy to reach and educate young people about reproductive health issues and to provide badly needed social support. Adolescents do not necessarily want to see their peers serving in these roles. They crave and value opportunities to learn and interact with positive adult role models, especially when they lack such models in their own homes.

\section{Livelihoods for young people- Much more than survival}

Jane Lowicki of the International Rescue Committee (IRC) discussed the challenges of implementing adolescent livelihoods programming in war-affected areas. The term "war-affected areas" encompasses a wide range of situations (including emergencies and postconflict conditions) and populations (refugees, internally displaced persons, and those living within or outside of camps). Yet earning a livelihood is a topic that young people consistently report as one of their primary concerns. Addressing adolescents' livelihood needs is one of the most difficult challenges facing the humanitarian community today.

Adolescents comprise a significant proportion of populations affected by armed conflict (more than 30 percent of such populations are aged 10-25), and they are affected in age- and genderspecific ways. Compared with younger children, adolescents are more likely to be forcibly recruited into fighting forces, miss out on education, be sexually abused (especially girls), and become heads of households. Most refugee and internally displaced adolescents are not in school; in emergency settings, educational efforts are usually aimed at children of primaryschool age. Instead, many adolescents are working hard to sustain themselves, their families, and their communities.

Young people in these circumstances employ a wide range of survival strategies, including fixing shoes, garbage picking, translating, and performing domestic 
work. Some rely on humanitarian assistance, but young people usually are unable to gain access to such assistance on their own; they require an adult connection. Where livelihood options are especially limited, adolescents may undertake activities that are harmful to themselves, for example, soldiering, engaging in sex work, or marrying early.

Young people say that having a livelihood represents more than mere survival. It means:

- the achievement of adulthood, which brings community and self-respect;

- self-reliance-the ability to care for oneself and for others, including one's own children;

- material resources-the ability to afford medical care and medicine, clothing, shoes, and shelter;

- an alternative to armed activities with fighting forces, gangs, or other groups;

- protection from sexual violence and exploitation;

- economic development and the chance for a better future;

- psychosocial healing; and

- the ability to marry or to avoid early marriage.

Recognizing the importance of addressing adolescents' livelihood needs, the IRC has undertaken activities that include skills training, apprenticeships, and microcredit schemes. Particularly vulnerable adolescents are targeted, such as former soldiers; orphans who are left without family as a result of AIDS, war, or other reasons; adolescent heads of households; and those who have been subject to violence or sexual abuse. For example, in eastern Guinea, the IRC has partnered with a local aid organization, Today's Women International Network, to provide vocational and literacy training to adolescent girls in refugee camps and in their host communities, many of whom previously worked in the sex industry. Training is offered in conjunction with counseling, so that participants can process and cope with their past experiences and find support as they move forward.

Livelihoods programs in areas of armed conflict face numerous challenges. Participants often find few outlets for their newly acquired skills where poverty is generalized and markets are weak. Markets may be glutted with workers having similar skills. Adolescent girls are frequently "invisible" where traditional gender roles remain strong, and special efforts may be required to ensure girls' participation. Humanitarian expenditures overall are not properly targeted at the specific circumstances and rights of adolescents and young people. Education should be a priority for adolescents as well as for children and should include livelihoods elements, such as teaching vocational and entrepreneurship skills.

In closing, Ms. Lowicki suggested some future directions that should be taken to support the livelihoods, protection, and development of young people 
in war-affected areas: (1) support young people's capacities and participation by increasing bilateral support and holding governments and humanitarian agencies accountable for such efforts; (2) incorporate educational programs for young people in emergency situations, including formal schooling (especially at the secondary level), informal education, and livelihoods-skills training; (3) link skills training to market needs; (4) provide training in business skills, such as planning and savings; and (5) identify and facilitate mentoring and apprenticeship opportunities. Humanitarian organizations cannot succeed at these efforts alone; stronger linkages must be made with the development sector to support adolescents at all phases of emergency and postconflict situations.

\section{Discussion}

Participants agreed that addressing girls' social disadvantages was crucial to the success of interventions and discussed the difficulties of turning a group experience into a solidarity experience. For some girls, having an alternate group identity, one that is not related to their families, develops their sense of self and can function as a source of power. Some noted that such a process requires a longer period of time and a more intensive meeting schedule than that which is currently planned in many programs.
When shaping program content for adolescent girls, one participant reminded the group not to forget that "girls just want to have fun." The dimension of enjoyment can be lost in curriculums loaded with modules dealing with HIV/AIDS, poverty, and gender inequity. Between their school and domestic responsibilities, girls' leisure time is limited, and they want to spend this precious time in an enjoyable manner. A program in Bangladesh, for example, uses the country's rich history of street theater to involve adolescents.

Some challenges to implementing livelihoods projects that incorporate social elements were shared. Laying the groundwork for interventions may take longer than expected because intensive and repeated training of microfinance staff to provide social support to adolescents may be required. In choosing partners, smaller, newer organizations may be more open than established ones to taking risks and trying out new ideas. Older large organizations are likely to have fixed mandates and may be focused more on the volume as opposed to the quality of results. One participant suggested that much could be learned about leadership skills and organizing from developing connections with the social movements that young people are already involved in, such as union or labor movements. 


\section{Clarifying problem statements, setting benchmarks, and developing tools}

Many health-care programs have easily quantifiable, discrete outcomes (for example, increased child immunization rates, increased proportions of births attended by skilled personnel, and the like), but livelihoods programs are altogether different, especially adolescent livelihoods programs. Although they often aim to help adolescents with asset building and establishing good savings behaviors and more gender-equitable work roles, these are longer-term outcomes that may not be feasible to capture because of funding, staffing, and research constraints. To compensate, researchers have tried to test conceptual frameworks and establish intermediate outcomes that are more easily measured.

Evaluating livelihoods approaches has also been challenging because they are concerned with concepts that are still being developed and defined. Self-esteem, agency, social networks, and social connectedness are all domains that mean different things in different cultures, regions, and faiths.

Evaluation challenges also arise as a result of the nature of the intervention and of the population that is being targeted. Outcome indicators may have to be adjusted to reflect the steep learning curve that partner organizations experience as they try out new program models and content. By definition, adolescent livelihoods programs are trying to reach the most vulnerable young people, yet these populations are likely to be overlooked in surveys (for example, married girls), to drop out of programs as a consequence of their domestic burdens and the pressure applied by gatekeepers, and to be highly mobile (the poorest, least-educated girls are likely to be married early and to move to their marital homes).

\section{Livelihood assets and gendered HIV risk among young people in South Africa}

Kelly Hallman of the Population Council discussed how livelihoods fundamentally affect health behaviors and risks, and focused on the relationships between socioeconomic status, social connectedness, and the risk of acquiring HIV in South Africa. Although a sea change is underway, many policymakers and program managers still consider HIV/AIDS to be primarily a medical and public health problem and implement interventions that focus solely on changing individuals' risky behaviors. These strategies often neglect to take into account the ways in which the social and economic realities of daily life structure risk, factors that are crucial to understand in the South African context, which is characterized by high HIV prevalence and high rates of poverty and inequality. HIV disproportionately affects young people and women in South Africa; young women aged 15-24 are more than three times more 
likely than young men to be HIV-positive (with prevalence rates of 16 percent and 5 percent, respectively) (Pettifor et al. 2004).

To establish the links between poverty, lack of social cohesion, and HIV risk, Dr. Hallman analyzed data from the 2001 survey of the "Transitions to Adulthood in the Context of AIDS in South Africa" conducted in KwaZulu-Natal province in South Africa. Socioeconomic status was operationalized by constructing an index of household wealth based on ownership of 23 physical, financial, and natural assets, and dividing respondents into quintiles. Social connectedness was measured using a sevenquestion survey producing an index that was also broken into quintiles. Adolescents were asked if they agreed or disagreed with such indicators as "I feel safe walking around in my community during the day."

Economic disadvantage was found to affect a number of aspects of HIV risk for both young women and men; often a stronger association was found for young women. Low socioeconomic status increases the odds of having had multiple sexual partners in the year before the survey and lowers age at sexual debut, the odds of condom use at last sex, communication with the most recent sex partner about sensitive topics, and access to media sources for family planning information. Poverty also affects girls disproportionately in other ways: Low socioeconomic status increases the odds that girls will exchange sex for money or goods, experience coerced sex, and experience early pregnancy. Moreover, a clear positive effect of wealth on social connectedness exists for girls but not for boys, although, remarkably, fewer girls in even the highest wealth quintile agree with the statement "I have many friends in my neighborhood" than do the poorest boys.

Dr. Hallman found associations between low social connectedness and earlier sexual debut, with higher risk of coercive or economically motivated sexual encounters, with lower negotiating power in sexual relationships, and with lesser wealth. These patterns were clear and consistent. For example, girls in the lowest quintile of social connectedness were more than four times more likely than those in the highest quintile ever to have been forced to have sex.

A livelihoods approach may be able to increase the effectiveness of health interventions by building the social and economic skills and assets of the poor. Strategies need to take into account the gendered way in which economic disadvantage and social connectedness affect behavior and to focus on improving girls' bargaining positions within their relationships, households, and communities.

\section{UCSF Women's Global Health Imperative: Adolescent Livelihoods and Reproductive Health}

Marty Gross and Lyndah Sibanda of the University of California, San Francisco's Women's Global Health Imperative (WGHI) presented their work on an integrated economic and life-skills intervention. WGHI's adolescent livelihoods proj- 
ects in India, Mexico, the United States, and Zimbabwe are designed to test their hypothesis that interventions that develop girls' economic power will enhance their decisionmaking ability concerning when, how, and under what circumstances they have sex, ultimately reducing their risk of acquiring HIV and other sexually transmitted infections and of experiencing unintended pregnancy.

The project in Zimbabwe, SHAZ! (Shaping the Health of Adolescents in Zimbabwe), takes place in a setting of high HIV prevalence, extensive gender inequity, and rampant poverty. A growing number of adolescents are AIDS orphans and are compelled to become heads of their households and care for their siblings and other relatives. In poor households, boys are sent to school while girls stay at home, although the gender gap is narrowing overall.

Numerous economic pressures lead many girls to engage in transactional sex with older men- "sugar daddies," or "dharas," in the Shona language. Girls have little ability to negotiate condom use and are at increased risk of being raped or otherwise physically abused in these relationships. As one 16-year-old orphan noted,

Big dharas are dirty-minded. They only think about sex. Big dharas can force you because they say "nothing for nothing." It's a contract, and you can't say no. If you refuse, you stay poor. If you take his money and refuse sex, he will rape you. He will say, "You ate my money for nothing."
SHAZ! is targeted at 16-19-year-old out-of-school orphaned girls living in two suburbs of Harare: Epworth and Chitungwiza. Girls will form peer groups, receive life-skills education, entrepreneurship and skills training, and be matched with a local businesswoman who will act as a mentor. Those who develop business plans will be provided with microcredit services.

The project's conceptual framework specifies the mechanisms through which change will occur (see Figure 5). For example, in one hypothesized pathway, providing individuals with business training will result in increasing their knowledge, in turn leading to their generation of and control over economic resources, and ultimately improving their abilities to negotiate safer sex, thereby reducing the incidence of HIV infection.

The study design for SHAZ! is a randomized controlled trial, with the intervention group receiving the life-skills and livelihoods components, and the control group receiving only the life-skills component. An enumeration of all orphans in the study areas will be conducted, after which 1,000 girls will be placed randomly in the intervention or control groups. The intervention will run for one year with a two-year follow-up period.

The groundwork is being laid for the larger study. Local partners have been identified and trained, the intervention curriculum and research tools have been developed, and a pilot study is underway. SHAZ! recruited 200 girls during the crosssectional phase and 50 girls in the pilot 
Figure 5 Conceptual framework of the SHAZ! Project, Zimbabwe

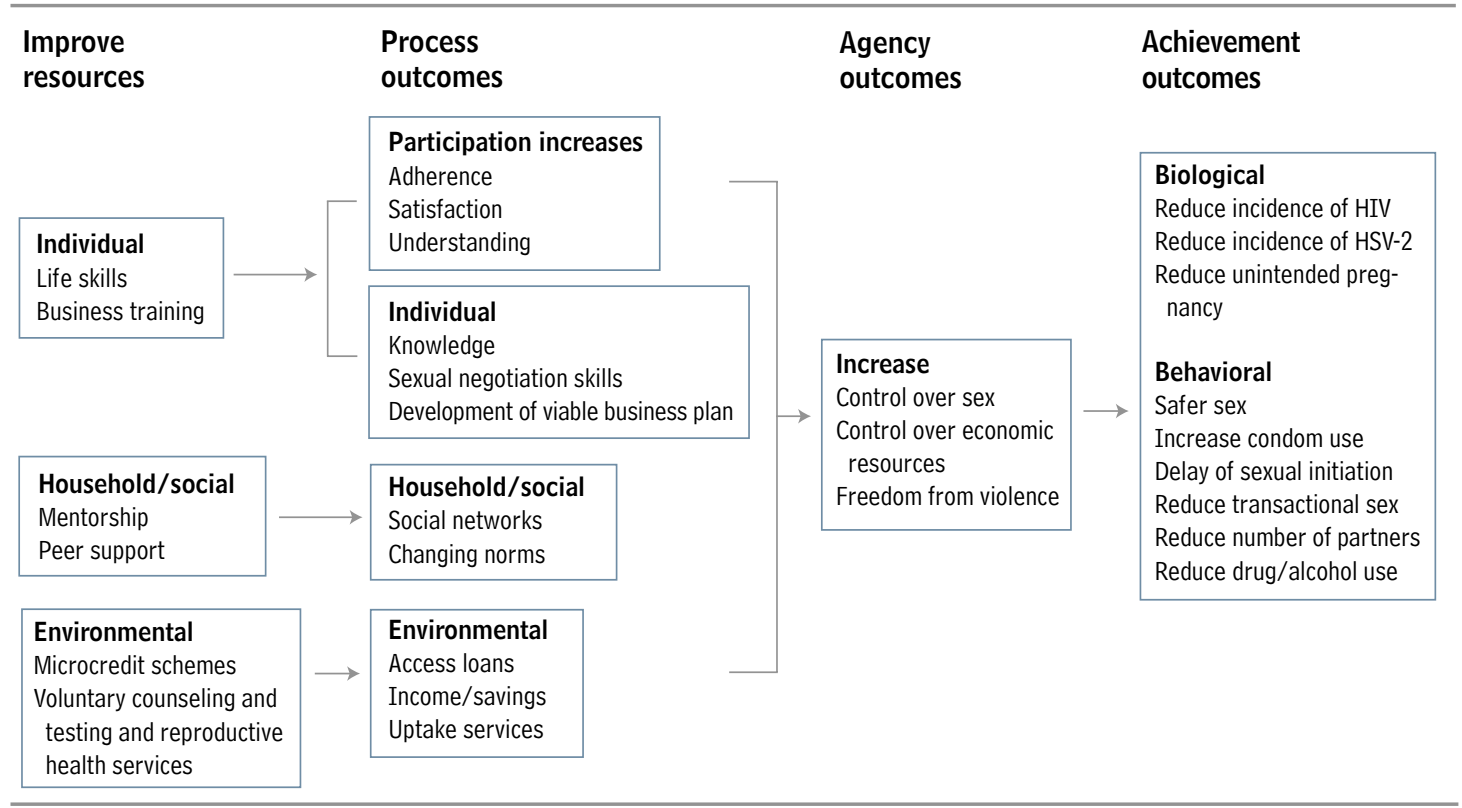

program. The pilot ended in December 2004, and the team is analyzing the results in order to refine the intervention and evaluation tools.

Numerous challenges are inherent in this type of study design. Adolescents are a mobile population, especially girls who are out of school and poor. Most likely, they will marry and move away or migrate for work during the intervention period, making follow-up and retention difficult. A randomized study requires that girls in the same community may be in different treatment groups, making treatment diffusion and intermingling of participants likely. Ethical issues include maintaining confidentiality and providing support to HIV-positive girls, and withholding a potentially beneficial program. If an effect is found after the evaluation, the livelihoods component will be offered to both groups.

\section{Thinking it through from programming to measurement: The easy, the difficult, and the impossible}

Martha Brady of the Population Council presented the evaluation framework for the Ishraq program in Egypt ${ }^{6}$, and discussed some of the measurement challenges their team faced. Questions of measurement and evaluation are particularly salient at this juncture as the project is in the process of being scaled up to reach many more girls in more villages in the poorest governorates of Egypt.

Ms. Brady detailed the stepwise process of developing the project, beginning with formative research. By analyzing existing data sets such as the Demographic and Health Survey and the Adolescence

\footnotetext{
${ }^{6}$ Alyce Abdalla described above the main features of the Ishraq project and its effects on building the social capital of participating girls (see page 26).
} 
and Social Change in Egypt survey, conducting qualitative research in the catchment area, and carrying out key-informant interviews with local service providers, the research team defined seven key problems in Al Minya area:

- As girls approach puberty, social pressures and customs restrict their mobility and access to public spaces.

- Many girls become candidates for early marriage, with little say over the choice of husband or the timing of marriage.

- Girls' school enrollment is low and their opportunities for education are limited.

- Girls lack nonfamilial social support.

- Girls describe themselves as being "ignorant."

- Girls have no opportunities for group sport and recreation.

- Boys dominate public space and harass girls who move in these spaces.

Given these problems, relevant target groups were defined. Because of the importance of reaching girls with the intervention before the marriage process was complete, the primary target group was defined as girls aged $13-15$ who were out of school and came from poor households. In this conservative area, girls can effect only minimal change if their external environment does not also change. Therefore, secondary target groups were also identified — parents, boys (especially brothers), community leaders, and promoters (slightly older girls who led the group activities).

Ishraq provided girls with an integrated package of interventions that included training in literacy and life skills as well as sports and recreation activities. Quantita- tive data were collected using baseline and endline surveys on all out-of-school girls aged 13-15 in the experimental and control villages and a midline survey on a subset of girls, and qualitative data were gathered by means of in-depth interviews and focus-group discussions with girls, parents, brothers, and promoters; case studies of program participants; and direct observation of program functioning.

For the literacy component, measurement indicators included program attendance, acquisition and retention of material, passing the government exam, the proportion accepted for schooling, and the proportion that returned to school. Ninetytwo percent of Ishraq participants who took the government literacy exam passed, and most want to continue their education.

The life-skills component was composed of a broader package, incorporating both knowledge and attitudes, and was more challenging to measure. Baseline and endline surveys contained items on knowledge of key health and rights issues, attitudes toward gender roles, and attitudes and decisionmaking concerning marriage. Important constructs such as selfefficacy, agency, social connectedness, and communication and negotiation skills were difficult to operationalize and to explain to participants in a culturally relevant way. The project team is continuing to analyze the data to see how successfully these constructs were captured. Initial results, however, suggest that Ishraq positively influenced girls' sense of agency: Girls' reported self-confidence improved dramatically; 52 percent believed them- 
selves to be "strong and able to face any problem." They increasingly expressed a desire to marry at older ages and to have a say in marriage negotiations.

The sports component was more straightforward to measure. The research team agreed that they were less interested in measures of competency than in whether the girls were exposed to new activities and found them to be fun. The measures included participation in teams and sessions; parents', boys', and girls' attitudes toward the appropriateness of sports for girls; and girls' future aspirations with regard to playing sports or being part of a team. Both in terms of attitudes and daily realities, the Ishraq program has increased girls' participation in sports activities. Beneficiaries now participate regularly in athletic activity, even though fewer than half had ever played sports prior to joining Ishraq.

Perhaps most important are changes at the institutional and community levels that will be far-reaching and longstanding. Many of these changes are not specifically attributable to any one component of Ishraq. For example, girls were issued public identification cards-a first and critical step in developing an active citizenry. Villages dedicated "girlsonly" spaces, allowing graduates of the programs to continue to meet and learn together. Ishraq graduates and promoters are participating in and leading community development activities. The Ministry of Youth and Sports and the National Council for Childhood and Motherhood embraced Ishraq as an important program model and plan to expand Ishraq activities, bring- ing them to the three most conservative Upper Egyptian governorates.

Certain issues remain that may be of major importance to Ishraq's goals but are not feasible to measure yet. These include: girls' transition to formal schooling; the process and timing of marriage and spouse selection; the health and social dimensions of the transition to motherhood; and girls' economic activities and access to financial resources. These are longer-term outcomes that will manifest themselves in years to come; the project team hopes to continue to follow graduates over time.

The Ishraq program has a unique ability to reach girls who are underserved, neglected and often ignored by other programs, and to provide them with new opportunities for learning, training, and active participation in the lives of their communities. As Ishraq is scaled up, special attention will be paid to (l) strengthening the training, deployment, and capacity of the program's promoters; (2) actively engaging parents and community leaders in the program; (3) including girls at ages younger than 12 in the program: (4) strengthening institutional ties with formal schooling; (5) enhancing livelihoods activities; and (6) developing a community and parent contract mechanism to ensure the program's success and sustainability.

\section{The effect of a livelihoods} intervention in urban slums in India: Do vocational counseling and training alter the attitudes and behaviors of adolescent girls?

Monica Grant and Mary Sebastian of the

Population Council presented the results 
of an experimental intervention for girls aged 14-19 in an urban slum in India that provided reproductive health information, vocational counseling and training, and assistance with opening savings accounts. ${ }^{7}$ Both the nature of the target population and the setting posed several methodological challenges that made evaluating the project difficult.

The project was conducted in the slum areas of Allahabad, approximately 600 kilometers from Delhi, in the northern state of Uttar Pradesh. Allahabad has nearly one million residents (Census of India, 2001), and that number is growing rapidly as a result of a dearth of job opportunities in the rural areas of Allahabad District. For this project, the Population Council collaborated with CARE, which had been implementing an intervention concerning young women's reproductive health issues in these slum areas since 1999 entitled Action for Slum Dwellers' Reproductive Health, Allahabad (ASRHA).

The underlying premise of the livelihoods intervention was that multiple benefits can accrue from synthesizing economic, social, and reproductive health activities. Specifically, the researchers examined whether an experimental intervention for girls aged 14-19 that provided vocational counseling and training and assistance with opening savings accounts in slum areas of Allahabad:

- increased their physical mobility and contact with individuals outside the family and their awareness of safe places in which to congregate;

- increased their self-efficacy;

- increased their reproductive health knowledge;

- altered their work aspirations and encouraged more progressive gender-role norms; and

- reduced the time they spent on domestic tasks and increased the time they spent on productive tasks.

A quasi-experimental pre- and posttest design was used, comparing girls in five intervention-area slums with girls in nine control-area slums. Girls in the control group participated only in the ASRHA reproductive health activities, while girls in the intervention group additionally received vocational counseling provided by peer educators, vocational training, and assistance in opening savings accounts.

Peer educators formed groups of about 15-30 girls and met weekly (usually in the peer educator's home), sharing reproductive health information, and offering vocational and savings counseling. Based on the girls' interests and the potential usefulness of the skill, 18 vocational courses were developed, ${ }^{8}$ which ranged in duration from one week to four months. Nearly 500 girls completed at least one course, and about 400 girls attended more than one course.

Although assistance was provided for opening savings accounts at either

\footnotetext{
${ }^{7}$ This summary draws substantially on Mensch et al. (2004).

${ }^{8}$ Courses arranged by the project included tailoring, mehndi (painting of hands or feet), creative painting, rug weaving, mending and embroidery, candle making, bee keeping, food preservation, and basic cooking.
} 
banks or post offices, most of the new accounts were opened at post offices, which required simpler procedures and smaller sums for initial deposits. Only 250 girls opened savings accounts; that this number was not greater was, perhaps, the result of difficulties the girls encountered with post-office staff who expressed their distaste for working with girls, chastised the girls for disturbing their work, and sometimes even harassed the girls.

The researchers encountered several difficulties in conducting a longitudinal survey of adolescents in the slum areas that were inherent aspects of the target population and the study areas. The fieldwork was conducted by the Centre for Operations Research and Training, the organization responsible for the National Family Health Survey (NFHS) in Uttar Pradesh.

One complication of data collection was the relative invisibility of married adolescents. For the baseline survey (conducted in April-June 2001), 3,199 eligible adolescents were interviewed, of whom only 2 percent of female respondents reported ever having been married. This finding suggests that married adolescent girls were significantly underrepresented in this survey, because 16 percent of 15-19year-olds in urban areas reported being married in the 1998-99 NFHS. This result was partly the consequence of a linguistic mistake: The Hindi word for adolescent or youth (kishori) used in the survey implies that the person referred to is unmarried. Other possible contributing factors could include families' desire to hide an illegal underage marriage (the legal age of mar- riage for girls is 18), or the perception that married adolescents are adults.

When the endline survey was conducted in the spring of 2003, a considerable effort was made to improve the coverage: 6,148 adolescents were interviewed. This dramatic increase in the number of eligible adolescents who were identified, although perplexing, can be explained, perhaps, by the differential diligence of the data-collection teams or by the increased willingness of adolescents and parents to be interviewed as they became more accustomed to the presence of researchers in the area.

Not only were numerous adolescents interviewed in the endline survey who were not interviewed at baseline, but 1,312 young people who were interviewed at baseline were not interviewed at endline. Some of this loss is to be expected because of the relative mobility of slum populations and because adolescent girls who married likely moved to their conjugal households, outside of the study area.

Despite these challenges, the project was able to demonstrate short-term changes in the outcomes of interest. Multivariate analysis indicated that girls exposed to the intervention were significantly more likely than those who were not to have knowledge of safe spaces, to be a member of a group, to score higher on a social skills index, to be informed about reproductive health, and to spend time on leisure activities. Reflecting on the intervention, the researchers noted that it was of too short a duration and insufficiently intensive to affect some of its broader goals related to gender 
disparities and decisionmaking power.

Substantially greater resources than were available for this study must be provided for proper evaluation of interventions with adolescents in urban slums.

\section{An adolescent livelihoods intervention in an early-marriage setting: Evaluation issues}

Sajeda Amin of the Population Council shared some of the evaluation challenges she encountered in implementing a livelihoods intervention for adolescents in rural Bangladesh. The program, Kishori Abhijan, was designed to increase age at marriage and school retention in three districts.

Study-design issues of concern included the different approaches of implementing organizations, the selection of participants, and the randomization of villages to intervention groups.

The Council worked in partnership with two Bangladeshi nongovernmental organizations, BRAC (formerly the Bangladesh Rural Advancement Committee) and the Center for Mass Education in Science (CMES). These two NGOs differ in scope and organizational culture: BRAC is a vast organization working in more than 60,000 villages. In order to function efficiently, decisions are made at the top and communicated vertically. In contrast, CMES is a much smaller organization and operates less bureaucratically; it is not uncommon for the director to be involved in implementing an intervention. Three types of programs were implemented: BRAC (APON), which consisted of life-skills activities; BRAC (JVO), which incorporated microcredit activities in addition to life skills; and the CMES program, which also had life-skills and livelihoods components.

Largely by design, participants in Kishori Abhijan were not representative of the general population of adolescents. Because a main objective of the program was school retention, the program focused on girls who were currently in school or had previously attended school. For example, 29 percent of all in-school girls in the program villages participated in the program, compared with 15 percent of all out-ofschool girls. Similarly, because the other key objective was to delay marriage, the majority of participants were young and unmarried. In addition, BRAC and CMES established their own criteria for membership: BRAC gave preference to girls who were in BRAC schools, whereas CMES restricted its enrollment to unmarried girls.

Villages were randomly assigned to intervention or control groups; however, randomization to APON or JVO programs proved to be complicated. (Because CMES worked in only 15 villages, it did not encounter these issues.) BRAC program organizers are responsible for about 15 villages each, but individual villages were used as the unit of randomization. Thus, if staff were trained to deliver the livelihoods component, they may have imparted some of the information to members in all villages instead of only to the subset selected to receive the JVO program. Complicating matters further, BRAC routinely transfers its staff from one area to another, which has the potential of contaminating the research design. A staff 
member who is trained to carry out a particular program may inadvertently carry it over to a nonprogram village under his or her supervision, so that program effects are diffused into nonprogram areas.

Despite the influence of these design concerns, the program was able to demonstrate several significant effects. Compared with nonmembers in intervention villages and girls in control villages, members were more likely to retain some or all of their income (84 percent for members versus 66 percent for nonmembers and 65 percent for controls). Members also reported less social isolation and greater mobility than nonmembers in terms of being able to visit specific locations such as the market or the movies. Although school drop-out rates appeared to be reduced to some degree by the intervention, marriage pressures remained a powerful determinant: Drop-out rates were more than two times greater among girls for whom marriage and dowry discussions had been held than among girls who had held no such discussions (35 percent versus 14 percent).

\section{Discussion}

Evaluating whether program participants have acquired a certain vocational skill is much easier than assessing the longerterm benefits of such programs. Determining if participants are more likely than nonparticipants to obtain paid work, to have some say in choosing their spouse, or are able to seek health care on their own requires significant human and financial resources for follow-up, and these outcomes are unlikely to be captured within many projects' time frames.

Some participants struggled with how to account for selection biases; projects may produce the desired outcomes, but they may be working with those who are predisposed to change. Less than a third of the participants who were offered credit in a Bangladeshi program accepted it. Programs that are supply driven will tend to recruit the "cream," those who are most able to take advantage of benefits, and not reach out to the neediest.

The plans to scale up the Ishraq project prompted comments about determining which components of "boutique" projects can be retained and brought up to scale and which components are of central importance in achieving the projects' objectives. One participant felt that Ishraq was too expensive to scale up, but others argued that the cost was not prohibitive in relation to what it could achieve nor in relation to other large-scale schooling programs. A participant noted that people tend to assume that whatever is happening now is good and that change is risky; yet in her opinion, large sums currently are being wasted on programs for adolescents such as youth centers and peer education. Programs that are evidence-based and thoroughly evaluated are less risky than those with vague objectives and nonspecified target groups. 


\section{Wrapping up and looking forward}

The evident diversity of adolescents' experiences (by age, sex, marital status, schooling, and living arrangements), of institutional features, and of partner organizations' characteristics across regions and even across communities, lends support to the already strong argument for evidence-based programming. In-depth analysis can identify the most vulnerable adolescents and determine the critical moments for intervention. These processes will help programs be more beneficiary driven, rather than supply driven.

Ideally, livelihoods programs can assist young people to envision a future different from what they might have expected and to open their eyes to the opportunities that occur. Beyond teaching vocational skills, programs should foster an enabling environment that allows young people to spot opportunities and cultivate them. The influence of globalization, in particular, causes markets to change constantly, and to be successful, workers will need to adapt to different environments.
Linkages with employers, governments, other social movements, and the private sector should be fostered; a number of interested parties and resources have yet to be fully used. Increased communication of research results and lessons learned from adolescent livelihoods program implementation would be useful at this early stage.

Assessment of both short-term and long-term outcomes are important in building the evidence base. Process data and intermediate indicators can assist in justifying the continuation of a program to donors and community members. Answering the broader questions, however, may require intensive monitoring for several years.

In closing, Judith Bruce put forward five key issues, distilled from the first generation of livelihoods projects for adolescents that should receive special attention when the second generation of projects is planned (see Box 4). 


\section{Box 4 Five propositions for discussion in developing a second generation of livelihoods programs for adolescents}

1. Livelihoods programs developed initially for adults need careful adaptation to benefit adolescents:

- Content should be appropriate for adolescents and build on their knowledge and experience.

- Training approaches should be achievement-based, interactive, and lively.

- Program staff should be trained both in new content and in effective ways of interacting with adolescent girls.

- Savings and credit schemes should be offered in conjunction with social support and mentoring.

2. Interventions should be staged, taking into account an adolescent's age, personal characteristics, and degree of poverty.

- "Entry-level" activities can be geared toward younger, more reserved, less economically integrated adolescents, and might include social groups with mentors, life-skills training, provision of health information, basic financial education, and voluntary savings opportunities. These activities should provide adolescents with a solid foundation and prepare them for the next level, which would add activities for better-prepared, more economically integrated adolescents.

- "Second-stage" activities potentially incorporate livelihoods training, instruction in taking out and repaying loans, exposure visits, and business-development training.

3. We must experiment to learn what content, be it literacy, sports, livelihoods training, savings, or reproductive health, is engaging to girls, is acceptable to and even creates demand among parents, and encourages sustained and regular participation.

4. We must learn how program content and group formation and social support interact to:

- increase acceptance and participation;

- increase the effective acquisition of skills; and

- increase the probability that participants can apply new skills.

5. We must develop different ways of studying and evaluating experimental and more mature second- and third-generation interventions for adolescents, including the criteria used to determine "success." Depending upon the stage of the intervention, appropriate benchmarks may be: demonstrating feasibility; garnering community support; developing organizational capacity to handle new material or work with a new target group; securing political commitment and government resources; and demonstrating positive impacts or effective scale-up. 


\section{References}

Amin, Sajeda and Nagah Al-Bassusi. 2003. "Wage Work and Marriage: Perspectives of Egyptian Working Women." Policy Research Division Working Paper No. 171. New York: Population Council.

Blenk, Werner Konrad. 2002. "ILO's Decent Work Agenda in Asia and the Pacific." Speech presented by Werner Konrad Blenk, the Director of the International Labour Organisation, Manila, May 2002. < http://www.ilo.org/public/english/region/asro/manila/info/dwaapsha.htm > . Accessed 25 May 2005.

Census of India. 2001. <http://www.censusindia. net>. Accessed 25 May 2005.

Hallman, Kelly and Monica Grant. 2004. "Poverty, educational attainment, and livelihoods: How well do young people fare in KwaZulu-Natal, South Africa?" Horizons Research Summary. Washington, DC: Population Council.

Kabeer, Naila. 2001. "Resources, agency, achievements: Reflections on the measurement of women's empowerment." In SIDA Studies, No. 3. Pp.17-57.

Mensch, Barbara, Monica Grant, Mary Sebastian, Paul Hewett, and Dale Huntington. 2004. "The effect of a livelihoods intervention in an urban slum in India: Do vocational counseling and training alter the attitudes and behavior of ado- lescent girls?" Policy Research Division Working Paper No. 194. New York: Population Council.

National Research Council and Institute of Medicine, panel on Transitions to Adulthood in Developing Countries, Cynthia B. Lloyd (ed.). 2005. Growing up Global: The Changing Transitions to Adulthood in Developing Countries, Washington, DC: National Academies Press.

Pettifor, A.E., H.V. Rees, A. Steffenson, L. HlongwaMadikizela, C. MacPhail, K. Vermaak, and I. Kleinschmidt. 2004. HIV and Sexual Behavior Among Young South Africans: A National Survey of 15-24-Year-Olds. Johannesburg: Reproductive Health Research Unit, University of the Witwatersrand.

Putnam, Robert. 2000. Bowling Alone: The Collapse and Revival of American Community. New York: Simon and Schuster.

Singerman, Diane and Barbara Ibrahim. 2001. "The cost of marriage in Egypt: A hidden variable in the new Arab demography." Cairo Papers in Social Science. Cairo: AUC Press.

Statistics South Africa. 2001. South Africa in Transition: Selected Findings from the October Household Survey of 1999 and Changes That Have Occurred Between 1995 and 1999. Pretoria: Statistics South Africa. 


\section{building assets for safe, productive lives}

\section{7-8 April 2004}

\section{participant list}

\section{Alyce Abdalla}

Population Council, Cairo

aabdalla@pccairo.org

\section{Susan Adamchak}

Population Council, Washington, DC sadamchak@pcdc.org

\section{Ayorinde Ajayi \\ Population Council, Accra,Ghana \\ aajayi@pcaccra.org}

\section{Sajeda Amin}

Population Council, New York samin@popcouncil.org

\section{Ragui Assaad}

Hubert Humphrey Institute/

University of Minnesota, Minneapolis

rassaad@hhh.umn.edu

\section{Asad Azfar}

Acumen Fund, New York aazfar@acumenfund.org

\section{Amy Babchek}

United Nations Foundation, Washington, DC

ababchek@unfoundation.org

\section{Jay Banjade}

Save the Children, Westport, CT jbanjade@dc.savechildren.org

\section{Martha Brady}

Population Council, New York

mbrady@popcouncil.org

\section{George Brown}

Rockefeller Foundation, New York gbrown@icrw.org

\author{
Judith Bruce \\ Population Council, New York \\ jbruce@popcouncil.org \\ Jennifer Catino \\ Population Council, Mexico City \\ jcatino@popcouncil.org.mx
}

\section{Erica Chong \\ Population Council, New York echong@popcouncil.org \\ Susan Davis \\ International Labour Organization, Geneva \\ thissdavis@aol.com}

\section{Gabriella DeVita \\ UNICEF, New York \\ mgdevita@unicef.org}

\section{Judy Diers}

Population Council, New York jdiers@popcouncil.org

\section{Peter Donaldson}

Population Council, New York pdonaldson@popcouncil.org

\section{Seydou Doumbia}

Population Council, Bamako, Mali sdoumbia@popcouncilmali.org

\section{Victoria Dunning}

United Nations Foundation, Washington, DC vdunning@unfoundation.org

\section{Annabel Erulkar}

Population Council, Accra, Ghana aerulkar@pcaccra.org 
Rachel Goldberg

EngenderHealth, New York

rgoldberg@engenderhealth.org

Monica Grant

Population Council, New York

mgrant@popcouncil.org

\section{Martin Gross}

Women's Global Health Initiative-

UCSF, San Francisco

mgross@psg.ucsf.edu

Nicole Haberland

Population Council, New York

nhaberland@popcouncil.org

Kelly Hallman

Population Council, New York

khallman@popcouncil.org

\section{Barbara Ibrahim}

Population Council, Cairo

bibrahim@pccairo.org

\section{Rounaq Jahan}

Columbia University, New York

rj15@columbia.edu

\section{Anrudh Jain}

Population Council, New York ajain@popcouncil.org

\section{Shireen Jejeebhoy}

Population Council, New Delhi, India shireen@pcindia.org

\section{Shveta Kalyanwala}

Population Council, New Delhi, India shveta@pcindia.org

Steve LaVake

YouthNet/FHI, Arlington, VA

slavake@fhi.org

Connie Lee

Save the Children, Westport, CT clee@savechildren.org
Cynthia Lloyd

Population Council, New York

clloyd@popcouncil.org

Tanya Lobel

tanyaslobel@yahoo.com

Jane Lowicki

International Rescue Committee, New York

janel@theirc.org

Ellen Marshall

Consultant

em@goodworksgroup.net

\section{Janean Martin}

YouthNet/FHI, Arlington, VA

jmartin@fhi.org

\section{Linda Martin}

Population Council, New York

Imartin@popcouncil.org

\section{Rose Maruru}

Population Council, New York rmaruru@popcouncil.org

\section{Sanyukta Mathur}

International Center for Research on Women, Washington, DC smathur@icrw.org

\section{Melissa May}

Population Council, New York mmay@popcouncil.org

\section{Rosemary McCarney}

StreetKids International, Toronto mccarney@streetkids.org

\section{Manisha Mehta}

EngenderHealth, New York

mmehta@engenderhealth.org

Barbara Mensch

Population Council, New York

bmensch@popcouncil.org 
Carey Meyers

Population Council, New York cmeyers@popcouncil.org

\section{Mark Montgomery}

Population Council, New York mmontgomery@popcouncil.org

\section{Rick Olson}

UNICEF, New York

rolson@unicef.org

\section{Saroj Pachauri}

Population Council, New Delhi, India monica@pcindia.org

\section{Sara Peracca}

Population Council, New York speracca@popcouncil.org

\section{Amanda Ritchie}

Population Council, New York aritchie@popcouncil.org

\section{Lydia Saloucou}

Population Council, Ouagadougou, Burkina Faso

Isaloucou@popcouncil.bf

\section{K.G. Santhya}

Population Council, New Delhi, India santhya@pcindia.org

\section{Annemieke de los Santos}

UNFPA, New York

santos@unfpa.org
Mary Sebastian

Population Council, New Delhi, India mary@pcindia.org

\section{Jennefer Sebstad \\ Consultant \\ jsebstad@comcast.net}

\section{Lyndah Sibanda}

Women's Global Health InitiativeHarare, Zimbabwe

Isibanda@uz-ucsf.co.zw

\section{Kathleen Stack}

Freedom From Hunger, Davis, CA kstack@FreeFromHunger.org

\section{Anupama Tantri}

Women's Global Health Initiative-

UCSF, San Francisco

atantri@psg.ucsf.edu

\section{Veronica Torres}

StreetKids International, Toronto torres@streetkids.org

\section{Jim Tuite}

Population Council, New York jtuite@popcouncil.org

\section{Corinne Whitaker}

International Women's Health Coalition, New York

cwhitaker@iwhc.org

Nadia Zibani

Population Council, Cairo

nzibani@pccairo.org 